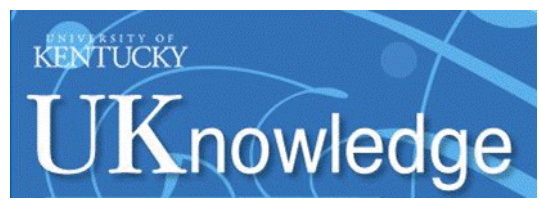

University of Kentucky

UKnowledge

\title{
WHEN BRAIN STIMULATION BACKFIRES
}

\author{
Sarah Beth Bell \\ University of Kentucky, sarah.beth.bell@uky.edu \\ Author ORCID Identifier: \\ (iD) https://orcid.org/0000-0001-6333-9026 \\ Digital Object Identifier: https://doi.org/10.13023/etd.2019.193
}

Right click to open a feedback form in a new tab to let us know how this document benefits you.

\section{Recommended Citation}

Bell, Sarah Beth, "WHEN BRAIN STIMULATION BACKFIRES" (2019). Theses and Dissertations-Psychology. 159.

https://uknowledge.uky.edu/psychology_etds/159

This Doctoral Dissertation is brought to you for free and open access by the Psychology at UKnowledge. It has been accepted for inclusion in Theses and Dissertations--Psychology by an authorized administrator of UKnowledge. For more information, please contact UKnowledge@lsv.uky.edu. 


\section{STUDENT AGREEMENT:}

I represent that my thesis or dissertation and abstract are my original work. Proper attribution has been given to all outside sources. I understand that I am solely responsible for obtaining any needed copyright permissions. I have obtained needed written permission statement(s) from the owner(s) of each third-party copyrighted matter to be included in my work, allowing electronic distribution (if such use is not permitted by the fair use doctrine) which will be submitted to UKnowledge as Additional File.

I hereby grant to The University of Kentucky and its agents the irrevocable, non-exclusive, and royalty-free license to archive and make accessible my work in whole or in part in all forms of media, now or hereafter known. I agree that the document mentioned above may be made available immediately for worldwide access unless an embargo applies.

I retain all other ownership rights to the copyright of my work. I also retain the right to use in future works (such as articles or books) all or part of my work. I understand that I am free to register the copyright to my work.

\section{REVIEW, APPROVAL AND ACCEPTANCE}

The document mentioned above has been reviewed and accepted by the student's advisor, on behalf of the advisory committee, and by the Director of Graduate Studies (DGS), on behalf of the program; we verify that this is the final, approved version of the student's thesis including all changes required by the advisory committee. The undersigned agree to abide by the statements above.

Sarah Beth Bell, Student

Dr. C. Nathan DeWall, Major Professor

Dr. Mark Fillmore, Director of Graduate Studies 
WHEN BRAIN STIMULATION BACKFIRES

\section{DISSERTATION}

A dissertation submitted in partial fulfillment of the requirements for the degree of Doctor of Philosophy in the College of Arts and Sciences at the University of Kentucky

By

Sarah Beth Bell

Lexington, Kentucky

Director: Dr. C. Nathan DeWall, Professor of Psychology

Lexington, Kentucky

2019

Copyright @ Sarah Beth Bell 2019 
ABSTRACT OF DISSERTATION

\section{WHEN BRAIN STIMULATION BACKFIRES}

tDCS brain stimulation does not always work in the intended direction. It has been found to sometimes worsen behavior rather than improve it. A preliminary study shows that people high on sensation-seeking and lack of premeditation were prone to reverse effects of tDCS on performance on a Stop Signal Task. Both of these constructs are related to dopamine levels. Study 2 seeks to intentionally cause a reverse effect of tDCS by increasing participants' dopamine levels via caffeine. There was not a significant interaction between tDCS and caffeine on errors on the Stop Signal Task in this study. However, other factors interacted with tDCS and caffeine including lack of premeditation. This two study package suggests the effects of tDCS are variable across individuals, with personality and neurochemistry both affecting behavioral outcomes of tDCS.

KEYWORDS: brain stimulation, reverse effects, impulsivity, tDCS, dopamine

Sarah Beth Bell

March 21, 2019 


\section{WHEN BRAIN STIMULATION BACKFIRES}

By

Sarah Beth Bell

\begin{abstract}
Dr. C. Nathan DeWall

Director of Dissertation

Dr. Mark Fillmore Director of Graduate Studies
\end{abstract}

March 21, 2019 
Dedicated to my dear cohort:

Brian Enjaian, Andrew Nelson, llyssa Salomon, and Taylor Elsey 


\section{ACKNOWLEDGEMENTS}

I greatly appreciate the research assistants who helped me collect the data for these studies: Simmie Nanda, Brian Turner, Rachel Barczak, Daniel Peng, Mariam Said, Shannon Ettinger, Sami Jabbour, Peyton Skaggs, Ndeye Amar, Alivia Houser, Korale White, Jessica Ryan, and Jonathan Arthur. They are lovely and intelligent people, and I could not have completed this endeavor without both their work and their support. 


\section{TABLE OF CONTENTS}

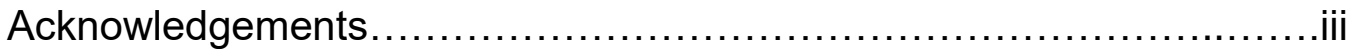

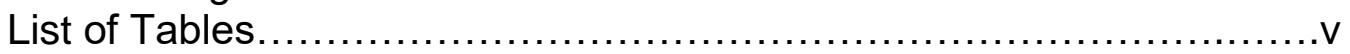

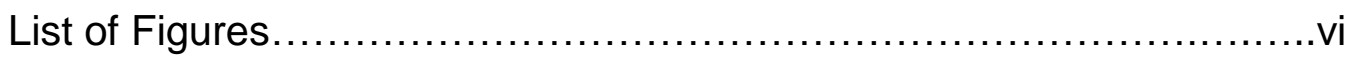

Chapter One:

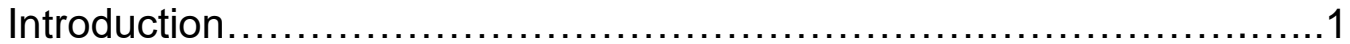

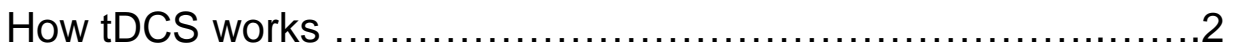

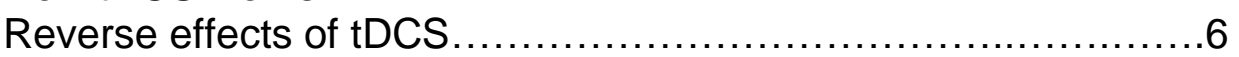

Sensation-seeking and lack of premeditation.....................6

Chapter Two:

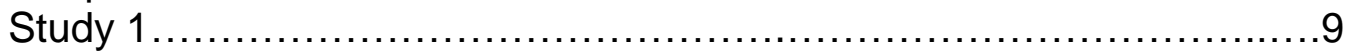

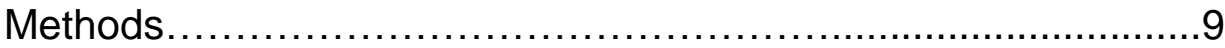

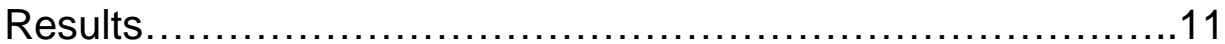

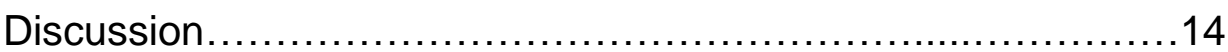

Chapter Three:

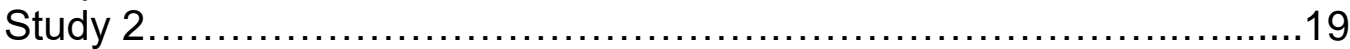

History of Manipulating Dopamine .............................19

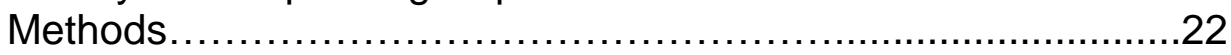

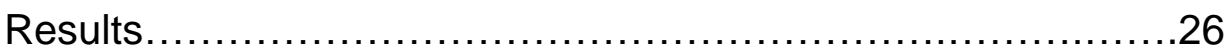

Chapter Four:

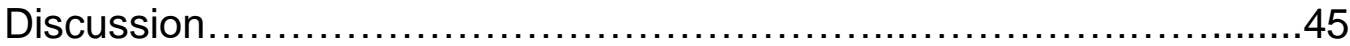

Limitations and Future Directions .............................. 50

Concluding Remarks......................................52

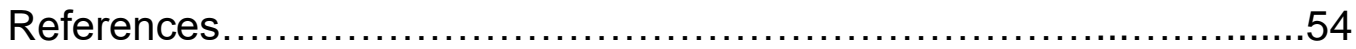

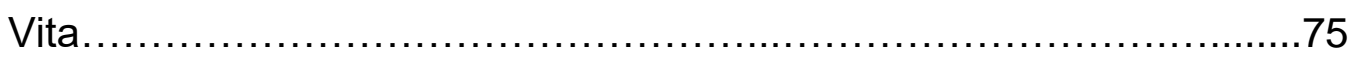




\section{LIST OF TABLES}

Table 1, Demographics in the Preliminary Study ..............................16

Table 2, Demographics in the tDCS and Caffeine Study ........................36

Table 3, Recreational Drug Use in the tDCS and Caffeine Study................37 


\section{LIST OF FIGURES}

Figure 1, Sensation-seeking and tDCS .................................17

Figure 2, Lack of Premeditation and tDCS ...............................18

Figure 3, tDCS and Caffeine's Effects on Error Rate.........................38

Figure 4, Lack of Premeditation and Error Rate...........................39-40

Figure 5, Stimulant Use and Error Rate.................................41-42

Figure 6, Hunger and Error Rate........................................43-44 


\section{Chapter 1}

Transcranial direct current stimulation (tDCS) helps targeted brain regions work better. But what happens when you have too much of a good thing?

A recent meta-analysis on tDCS and social behavior highlights mixed

findings. Although it finds that tDCS is effective at changing behavior, the effect is small at $d=0.20$ (Bell \& DeWall, 2018). This small effect is largely driven by tDCS sometimes making a behavior improve and sometimes making a behavior worsen. The paper included a forest plot that paints a vivid picture of how often these reverse effects of tDCS occur.

Although tDCS is not a drug, in many ways, it acts similarly to one. The dose of tDCS used can change how it affects people (Chhatbar et al., 2016; Hoy et al., 2013; Nitshe \& Paulus, 2000). In addition, there is already strong evidence that tDCS can affect different people in different ways (Chew et al., 2015; Datta, 2012; Kanai \& Rees, 2011; Katz et al., 2017; Kim et al., 2014; Krause \& Cohen, 2014). This is similar to how the same drug can affect two people in different ways.

For an example case, consider melatonin. It promotes sleep, so people who take it should feel more rested. However, in some people, it causes a reverse effect, making them groggy upon awaking (Andersen et al., 2006; Boeve 
et al., 2003; Muller et al., 2006). In this way, the drug is a good thing for some people, but too much of a good thing backfires for others.

It is becoming clear that tDCS is not a cure-all. Context and the individual brain chemistry both matter. A variety of researchers have stumbled upon socalled reverse effects of tDCS, where brain stimulation causes behavior to worsen rather than improve (see Fecteau et al., 2007; Gomez-Ariza, 2017; McLaren, Nissim, \& Woods, 2018; Monte-Silva et al., 2009). We are learning more about the role of the situation and individual brain chemistry in how tDCS works.

For another example, tDCS can be compared to caffeine. In the right amount, it can increase productivity, but with too much, it can make people jittery and anxious. In addition, some people do not respond well to caffeine at all, which relates to individual differences in brain chemistry (Alsene et al., 2003; Masi et al., 2016; Pickering \& Kiely, 2018). This does not mean the effects of caffeine have been debunked. Rather, overall caffeine can be helpful, as long as it is administered in the right dose, the right setting, and to a person who tolerates it well.

This paper will explain what we know about tDCS having reverse effects. Then, I will discuss the neurochemistry related to impulsivity and tDCS. Next, I will lead into a preliminary impulsivity experiment where tDCS had a reverse effect. Finally, I will propose a new study extending the findings of this preliminary study. 


\section{How tDCS works}

tDCS applies a tiny electrical current to a targeted region of the cortex,

making neurons in that region more likely to fire (Bennabi et al., 2015; Jacobson, Kozlowsky, \& Lavidor, 2012). The current is too small to cause a full action potential, but it brings neurons closer to firing through partial depolarization via the tDCS current (Brunoni et al., 2012; Fregni, 2005). Sham stimulation is used as the placebo for tDCS; the device is turned on, but automatically turns off after 90 seconds (Brunoni et al., 2012; Filmer, Dux, \& Mattingley, 2014).

Anodal stimulation applies an electrical current to a targeted area of the brain, and the current leaves the brain in a neutral location called the reference electrode. Cathodal stimulation can be characterized as the opposite of anodal stimulation. In cathodal stimulation, electricity is applied to the neutral reference electrode and leaves the brain in the targeted region (Brunoni et al., 2012; Filmer, Dux, and Mattingley, 2014). Anodal stimulation is excitatory, whereas cathodal stimulation is inhibitory (Brunoni et al., 2012; Filmer, Dux, and Mattingley, 2014). This study uses anodal stimulation to increase excitation and activity in the prefrontal cortex. Recent research suggests that excitatory tDCS and motivation work together to enhance ability (Bell \& DeWall, under review). tDCS has been used in a variety of social behavior realms. tDCS can reduce risk-taking behavior (Huang et al., 2017; Pripfl et al., 2013; Zheng et al., 2017), racial bias (Gladwin et al., 2012; Sellaro et al., 2008), and overeating (Georgii et al., 2017; Jauch-Chara et al., 2014; Ljubusavlevic et al., 2017). However, tDCS does not always change behavior in a socially desirable way. 
This phenomenon is partially driven by tDCS causing reverse effects in certain contexts.

These varied findings have sparked interest in how tDCS works in a variety of contexts. In the meta-analysis referenced at the beginning of this paper (Bell \& DeWall, 2018), the effects of tDCS on the prefrontal cortex were examined on multiple types of social behavior. tDCS affected these behaviors overall ( $d=0.20)$, even when correcting for publication bias. In this meta-analysis, six different types of social behavior were also examined individually, including impulsivity.

In the meta-analysis, tDCS on the prefrontal cortex did not affect impulsive behavior. This is largely due to the mixed findings in this area. Three studies showed thattDCS made people more impulsive, whereas four studies showed tDCS made people less impulsive, and the final study included was the present study (Bell \& DeWall, in press). To better understand these seemingly inconsistent effects, I will examine how individual differences in neurochemistry affect how tDCS works.

\section{Reverse effects of tDCS}

Medications including SSRIs (Kuo et al., 2016; Nitsche et al., 2009) and amphetamines (Brunoni et al., 2012; Nitsche et al., 2004) can potentiate tDCS. However, a variety of other medications have been found to reverse the direction of tDCS effects. Medications that can cause reverse effects with anodal stimulations include those that interact with GABA (McLaren, Nissim, \& Woods, 2018; Monte-Silva et al., 2010) and dopamine (Kuo et al., 2008). 
tDCS has also caused reverse effects in a variety of realms of behavior that relate to impulsivity. These include aggression, bias, and dishonesty. According to the $\mathrm{I}^{3}$ model (Finkel et al, 2014), aggression is partially driven by lack of inhibition. Inhibition, or lack thereof, is a key component of impulsivity (Bari \& Robbins, 2013; Kertzman et al., 2017).

Bias also relates to impulsivity. For example, Black Americans are more likely to be shot erroneously by police officers than White Americans (Correll, Urland, \& Ito, 2006; Scott et al., 2017). However, this effect is reduced when police have more practice shooting correctly rather than shooting impulsively (Correll et al., 2017; Plant \& Peruche, 2005). In light of these findings, impulsivity is a key factor in this issue and related racial bias issues.

Finally, dishonesty has been found to increase when an impulsive state is induced in participants. For example, Mead et al. (2009) mentally fatigued participants to decrease inhibitory capacity, which resulted in more impulsive cheating on a test. While aggression, bias, and dishonesty are different behaviors, they share an underlying factor: impulsivity.

tDCS to the prefrontal cortex has been found to increase aggression (Kelley et al., 2013), bias (Nord et al., 2017), and dishonesty (Colzaro et al., 2015). Previous research shows that impulsivity is particularly vulnerable to inconsistent or reverse effects (Bell \& DeWall, 2018). This may be driven by individual differences in impulsivity, which is closely linked to dopamine levels in the brain. 


\section{Impulsivity and reverse effects of tDCS}

Impulsive thoughts can result in decisions that are not well thought through, risky behaviors, and choices for short-term, small rewards over longterm, large rewards. Differing levels of dopamine are one of the driving factors in individual difference in impulsivity (Buckholtz et al., 2010; Dalley \& Roiser, 2012). Dopamine levels that are too low or too high can cause impulsive behavior (see Congdon et al., 2005 for review). This is why disorders related to impulsivity such as ADHD are treated with drugs that change dopamine levels in the brain (Dalley \& Roiser, 2012; Solanto et al., 2012).

We also know that dopamine levels that are both too low and too high are known to cause reverse effects in tDCS (McLaren, Nissim, \& Woods, 2018; Monte-Silva et al., 2009). Therefore, impulsivity is a perfect storm for tDCS to cause reverse effects in some people due to differing levels of dopamine between individuals. Three previous studies have already found tDCS to indirectly make people more impulsive in delay-discounting tasks, gambling measures, and error rates on a cognitive control task (Bell et al., in preparation; Fecteau et al., 2007; Gomez-Ariza, 2017). The present study examines the effect of tDCS on impulsivity.

\section{Sensation-seeking and lack of premeditation}

I hypothesized that people high in certain facets of trait impulsivity will experience a reverse effect of tDCS. The UPPS impulsivity scale (Whiteside \& Lynam, 2001) measures five facets of impulsivity: positive urgency, negative urgency, sensation-seeking, lack of premeditation, and lack of perseverance. 
Sensation-seeking and lack of premeditation are the two facets of the UPPS most related to dopaminergic function (DeYoung, 2013).

The relationship between dopamine levels and sensation-seeking has been clearly established (Derringer et al., 2010; Netter et al., 1996; Norbury et al., 2013). People high in sensation-seeking tend to have both highly reactive dopamine systems as well as weak serotonin and noradrenergic systems, which combine to produce the strong approach motivation that leads to sensationseeking (Zuckerman, 1996).

A common trait of ADHD is lack of premeditation, which is why ADHD is treated with medicine that changes dopamine levels (Arnsten, 1996; DeYoung, 2010). People with ADHD react to dopamine differently than other people. Sometimes their dopamine levels are too low, and sometimes their dopamine levels are too high. This is because they experience transient releases of dopamine in bursts, rather than more of a steady stream like people without ADHD (Aboitiz et al., 2014). One theory is that people with ADHD have low tonic dopamine levels but have overly large bursts of dopamine (also called hyperbursts) when attending to certain stimuli (Yanofski, 2010). Yanofski (2010) describes it as a problem of too little and too much dopamine. ADHD medication helps correct for this problem by bringing up tonic dopamine levels, which reduces the hyper-bursts of dopamine (Aboitiz et al., 2014). This type of dopaminergic malfunction is on a continuum, with people exhibiting varying levels of malfunction (Costa et al., 2013). 
Further evidence of the link between dopamine levels and lack of premeditation is provided by research on the Barrett Impulsivity Scale. This scale primarily assesses lack of premeditation (Cyders \& Canli, 2005; Whiteside \& Lynam, 2001). Scores on this scale predict D2 binding in the brain, further showing the link between dopamine and lack of premeditation (Buckholtz et al., 2010; DeYoung et al., 2013; Zald et al., 2008).

The other three traits on the UPPS scale-positive urgency, negative urgency, and lack of perseverance-show little relationship with dopamine (DeYoung et al., 2013). Dopamine drives exploration and approach motivation (Cohen et al., 2007; Daw et al., 2006) which relate to sensation-seeking and lack of premeditation, but not much to the other three traits (DeYoung et al., 2013). Dopamine levels that are too low or too high could cause reverse effects of tDCS. Therefore, since only sensation-seeking and lack of premeditation are strongly related to dopamine, and because dopamine levels are a precursor of impulsivity, I hypothesized that tDCS will cause reverse effects on people high in impulsivity in these two domains. 


\section{Chapter 2}

\section{Preliminary Study}

\section{Participants}

124 participants were drawn from the University of Kentucky subject pool. None of the participants took psychotropic medications. They also had to have never had a seizure, concussion, migraine, psychiatric disorder, substance abuse disorder, or learning disability. Demographics of these participants are described in Table 1 at the end of this chapter.

\section{Measures}

The Stop Signal Task measures response inhibition (Logan, 1994; Verbruggen et al., 2008). First, participants see a fixation circle. Then, an arrow appears in the circle. The arrow points either to the right or the left. The participant is instructed to rest her hands on right and left response keys and respond accordingly when she sees the arrow. However, sometimes a signal beep is played immediately after ( 250 milliseconds after) the arrow appears. When this happens, the participant is supposed to inhibit her response and not press any key. I used the probability of the participant pressing the response button after hearing the signal beep, when responses were supposed to be inhibited, as our outcome variable in this task. 
The Stop Signal tasks correlates to impulsivity in real life. It has been shown to be significantly related to scores on the Classroom Observation Code, a measure of impulsive and hyperactive behavior in school children (Solanto et al., 2001). Children with ADHD perform slower on the Stop Signal Task than their typically developing peers, $d=0.64$ (Nichols \& Waschbusch, 2004). When taking ADHD medication such as methylphenidate, this difference disappears (Nichols \& Waschbusch, 2004).

The Stop Signal Task sometimes has ceiling effects (Hsu et al., 2011; Rubia et al., 1998). Depletion manipulations cause more errors on the Stop Signal Task (Muraven, Rosman, \& Gagné, 2006). Therefore, to avoid a ceiling effect in this study, all of the participants underwent depletion measures during tDCS stimulation. They performed the Stroop Task (Stroop, 1935) followed by the Crossing Out E's task (as described in DeWall et al., 2008) over 10 minutes.

\section{Procedure}

Participants arrived at the laboratory, completed the UPPS, and then were exposed to the tDCS manipulation. By random assignment, participants experienced either excitatory or sham tDCS over the right ventrolateral prefrontal cortex (rVLPFC). The rVLPFC is a region of the brain implicated in impulsive behavior (Cohen et al., 2013; Lieberman \& Eisenberger, 2008; Narayan, 2010). To stimulate the rVLPFC, direct current was applied to the rVLPFC using a constant current regulator (DC-STIMULATOR, NeuroConn GmbH, Germany). The current was transferred using a saline-soaked pair of surface sponge electrodes placed on the participant's scalp. The stimulation (anode) electrode 
was placed over F6 (Montreal Neurological Institute coordinates: 58, 30, 8), whereas the reference (cathode) electrode was placed over the contralateral supraorbital area. To increase focality of stimulation, the stimulation electrode was $25 \mathrm{~cm}^{2}$ and the reference electrode was $35 \mathrm{~cm}^{2}$. All participants were told that they would receive either real or sham (placebo) stimulation for 20 minutes. Only half actually received a constant current of $1.5 \mathrm{~mA}$ (excitatory stimulation), while the other half received sham stimulation.

After the electrodes were comfortably attached, the stimulation began. Because tDCS takes about 10 minutes to become active in the brain (Riva et al., 2014), participants watched a nature video as a filler task. At the 10-minute mark, participants began depletion exercises for the remaining 10 minutes of stimulation. They performed the Crossing Out E's task and then the Stroop Task. After the 10 minutes elapsed, participants stopped these exercises.

After 20 minutes of stimulation, the tDCS ramped down and turned off, and the electrodes were removed from the participants. They then received instructions for the Stop Signal Task and completed it. After the Stop Signal Task, participants were fully debriefed.

\section{Results of preliminary study}

The mean probability of failure to inhibit on the Stop Signal Task was $50.21, S D=14.19$, which gave me fine gradation to see differences in performance across groups. I will refer to the mean probability to fail to inhibit on the Stop Signal Task as impulsivity. I did not find a main effect of tDCS on impulsivity $\left(M_{t d c s}=51.71, S D_{t d c s}=16.23\right.$ vs. $\left.M_{\text {sham }}=48.61, S D_{\text {sham }}=11.55\right), \mathrm{B}=3.43$, 
$t(122)=-1.22, p=0.236, d=0.23$. This is a similar to the $d=0.20$ effect size found in the meta-analysis referenced in the beginning of this manuscript (Bell \& DeWall, 2018).

I checked to see if there were significant differences between the sham and tDCS groups on MCQ scores as well as on any of the five dimensions of impulsivity. There were no significant differences between these two groups on these personality measures.

Two facets of the UPPS significantly interacted with tDCS, both resulting in tDCS increasing impulsivity in people high on these facets. Sensation-seeking interacted with tDCS to increase impulsivity, $B=2.16, t(122)=2.25, p=0.026$, $d=0.16$ (see Figure 1). To better understand the nature of this difference, I performed a simple slopes test to examine the effect of sensation-seeking on impulsivity among the sham and stimulation conditions, respectively. Among participants in the control group, sensation-seeking did not increase impulsivity on the Stop Signal Task, $B=-0.52, t(122)=-0.89, p=0.378$. But among participants who received tDCS, sensation-seeking predicted greater impulsivity on the Stop Signal Task, $B=1.64, t(122)=2.17, p=0.032$. To interpret this interaction, I tested the simple effects of tDCS on people who had low and high scores on the sensation-seeking task (one standard deviation below and above the mean; Aiken \& West, 1991). When looking at the people who were one standard deviation below the mean or low on sensation-seeking, tDCS did not affect impulsivity on the Stop Signal Task, $B=-2.72, t(122)=-0.75, p=0.452$. When looking at the people who were one standard deviation above the mean or high 
on sensation-seeking, tDCS significantly increased impulsivity on the Stop Signal Task, $B=8.96, t(122)=2.48, p=0.014$.

Lack of premeditation also interacted with tDCS on the Stop Signal Task, $B=3.43, t(122)=2.52, p=0.013, d=0.26$ (see Figure 2 ). To better understand the nature of this difference, I performed a simple slopes test to look just at the control group and then just at the tDCS group. When looking at the control group, lack of premeditation did not increase impulsivity on the Stop Signal Task, $B=-$ $0.90, t(122)=-0.98, p=0.329$. When looking at the group that received tDCS, lack of premeditation did significantly increase impulsivity on the Stop Signal Task, $B=2.54, t(122)=2.51, p=0.014$. I also tested the simple effects of tDCS on people who had low and high scores on the sensation-seeking task (one standard deviation below and above the mean; Aiken \& West, 1991). When looking at the people who were one standard deviation below the mean or low on lack of premeditation, tDCS did not affect impulsivity on the Stop Signal Task, $B=-2.97$, $t(122)=-0.84, p=0.403$. When looking at the people who were one standard deviation above the mean or high on lack of premeditation, tDCS significantly increased impulsivity on the Stop Signal Task $B=9.75, t(122)=2.73, p=0.007$.

These results do not correct for multiple comparisons. This is for two reasons. The first is because these analyses are explicitly exploratory. The second is to avoid type II errors in this exploration of the data (Gelman, 2012). A more extended discussion of this can be found in chapter four of this manuscript.

In the introduction, I discussed how sensation-seeking and lack of premeditation relate to dopamine levels, but the other three facets of impulsivity 
(positive urgency, negative urgency, and lack of perseverance) show little relationship with dopamine. None of the three facets of impulsivity unrelated to dopamine interacted with tDCS (positive urgency: $B=1.81, t(122)=1.66, p=0.099$; negative urgency: $B=0.46, t(122)=0.48, p=0.629$; lack of perseverance: $B=1.65$, $t(122)=1.06, p=0.291)$.

\section{Discussion of preliminary study}

In this study, I examined the effect of tDCS to the prefrontal cortex on error rate on the Stop Signal task, which measures impulsivity. In addition, I studied how trait levels of impulsivity affected the relationship between tDCS and performance on the Stop Signal task. Using the UPPS, I examined 5 subdomains of trait impulsivity: positive urgency, negative urgency, sensationseeking, lack of premeditation, and lack of perseverance (Whiteside \& Lynam, 2001). I examined whether tDCS differently affected people who were high on these facets $(+1 S D)$ and low on these facets $(-1 S D)$.

For people low on any of the 5 facets of impulsivity, tDCS had no effect on performance on the Stop Signal Task. However, a different pattern emerged for people high on both sensation-seeking and lack of premeditation. People high on these two facets experienced a reverse effect of tDCS, behaving more impulsively by making more errors on the Stop Signal Task.

Sensation-seeking and lack of premeditation are the only two facets of the UPPS impulsivity scale that relate to dopamine levels in the brain; the other three facets have little relationship to dopamine levels (DeYoung et al., 2013). People high on these two facets have different levels of dopamine in the brain than 
people low in these two facets on average (Buckholtz et al., 2010; Derringer et al., 2010; DeYoung et al., 2013; Norbury et al., 2013).

These findings show that individual differences in trait impulsivity influenced how tDCS affected people on the Stop Signal Task. These findings indirectly suggest that the effects of tDCS may depend on individual differences in dopamine levels. This mirrors previous research linking dopamine levels to reverse effects of tDCS (McLaren, Nissim, \& Woods, 2018; Monte-Silva et al., 2009).

While the results of this study suggest that dopamine levels affect how different people react to tDCS, I did not collect or manipulate dopamine levels in this experiment. A study that either collects dopamine levels or influences dopamine levels with medication would be a logical next step in studying the relationship between neurochemistry and the effects of tDCS. 
Table 1, Demographics of the Preliminary Study.

\begin{tabular}{|l|l|l|l|}
\hline Age & Mean & SD & Range \\
\hline & 18.6 years old & 1.2 years & $18-22$ years old \\
\hline Race & Asian & $2 \%$ \\
\hline & Biracial & $3 \%$ \\
\hline & Black & $12 \%$ \\
\hline & Hispanic & $4 \%$ \\
\hline & Other race & $3 \%$ \\
\hline Gender & White & $76 \%$ \\
\hline & Man & $25 \%$ \\
\hline & Woman & $75 \%$ \\
\hline & Other & $0 \%$ \\
\hline
\end{tabular}


Figure 1, Sensation-Seeking and tDCS.

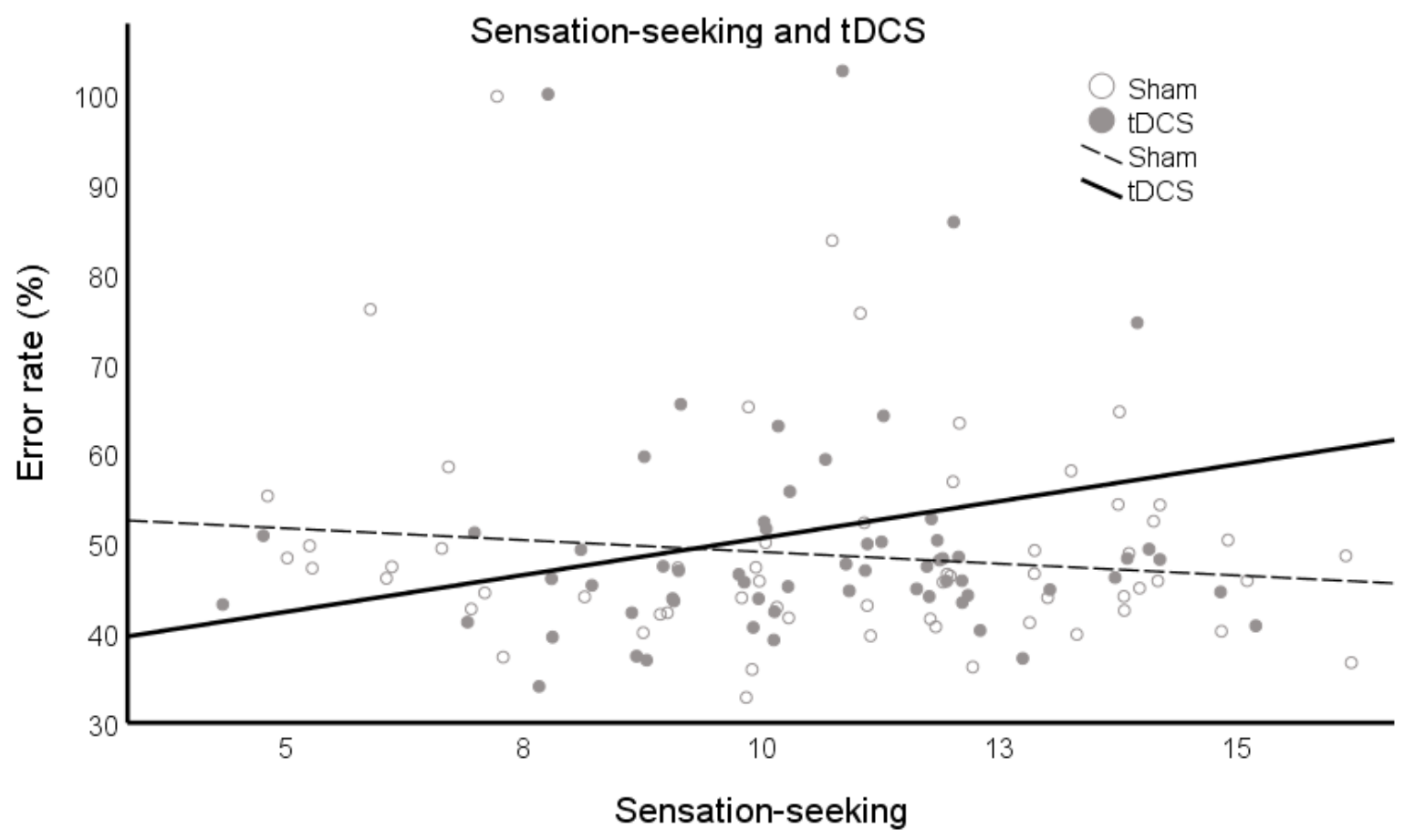

tDCS increased impulsivity in people who are high on sensation-seeking. 
Figure 2, Lack of Premeditation and tDCS.

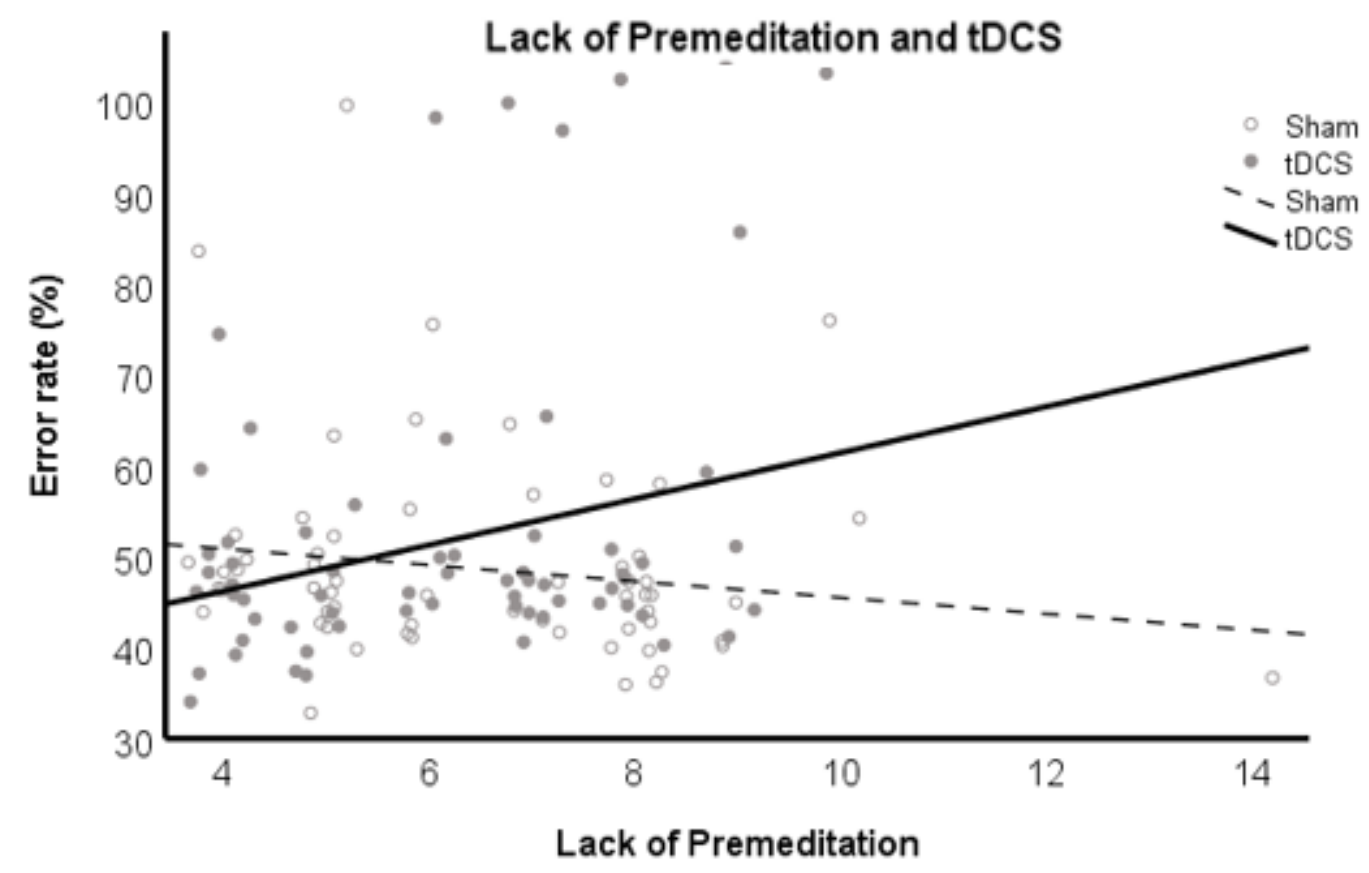

tDCS increased impulsivity in people who have a hard time premeditating their actions. 


\section{Chapter 3}

In the present study, I manipulated dopamine levels via caffeine. It has long been established that caffeine intake increases dopamine (Acquas et al., 2002; Cauli et al., 2005; Fredholm, 1995; Quarta et al., 2004; Solinas et al., 2002). More specifically, caffeine increases the available levels of dopamine in the shell of the nucleus accumbens (Quarta et al., 2004; Solinas et al., 2002). This is analogous to the effect of amphetamines on dopamine levels because amphetamines also increase dopamine levels in the shell of the nucleus accumbens (Boye, Grant, \& Clark, 2001; Parkinson et al., 1999).

The shell of the nucleus accumbens primarily contains medium spiny neurons with D1 or D2 receptors (Gruber \& O'Donnell, 2009; Lee et al., 2006; Li, Kolb,\& Robinson, 2003). The relationship between impulsivity and dopamine helps explain why activity in the nucleus accumbens is also closely linked with impulsive behavior (Basar et al., 2010; Dalley et al., 2007; Galtress \& Kirkpatrick, 2010). Brain stimulation itself also increases dopamine levels (Tanaka et al., 2013, Strafella, 2001). This has made it an exceptionally promising treatment for people with Parkinson's disease who have dopamine levels that are too low (Benninger et al., 2010; Boggio et al., 2006; Fregni et al., 2006). However, it may not be a good thing for impulsive people who often already have levels of dopamine that are too high (Buckholtz et al., 2010; Congdon et al., 2005; Dalley 
\& Roiser, 2012). Because too much dopamine has been found to cause reverse effects of tDCS (Kuo et al., 2008; McLaren, Nissim, \& Woods, 2018; Monte-Silva et al., 2009), we believe that caffeine administration during tDCS will increase dopamine levels too much, resulting in a reverse effect of tDCS.

\section{History of manipulating dopamine}

Only 70 years ago, dopamine was believed to be merely a byproduct in the synthesis of tyrosine to adrenaline and noradrenaline (Iverson \& Iverson, 2007). In 1957, in a hospital on the outskirts of London, Arvid Carlsson and his colleagues were conducting research with reserpine (Yeragani et al., 2010). Reserpine is used to treat blood pressure (Matson \& Mahen, 2010). In higher doses, this drug can cause people to be unable to move or talk (Matson \& Mahen, 2010). Because of this undesirable side effect, Carlsson and his colleagues experimented with giving people L-Dopa after taking resperidine (Yeragani et al., 2010).

Carlsson and his colleagues noticed that this L-Dopa treatment diminishes akinetic side effects of resperidine (Iverson \& Iverson, 2010). This discovery lead Carlsson and others to begin to see dopamine not merely as a byproduct in the synthesis of other neurotransmitters but also as potentially a neurotransmitter itself (Iverson \& Iverson, 2007; Yeragani et al., 2010). This discovery began the journey toward our modern understanding of dopamine.

Carlsson developed a way to measure dopamine levels using an assay (Carlson \& Waldeck, 1958). This led to the discovery of the link between schizophrenia and maladaptively elevated dopamine levels (Carlsson \& 
Lindqvist, 1963). Haldol was invented to help treat schizophrenia by partially blocking some dopamine receptors, reducing the amount of available dopamine in the brain (Carlsson \& Lindqvist, 1963; Carlsson, 1988). Now, we still use Haldol to treat schizophrenia, and more commonly use Seroquel, which works similarly to Haldol (Arvanitis \& Miller, 1997; Copolov et al., 2000). Schizophrenia is primarily treated by manipulating dopamine levels.

This dopamine and schizophrenia link is related to a psychiatric emergency called amphetamine induced psychosis. In this type of psychosis, a person consumes too much amphetamine, elevating their dopamine to a psychiatrically dangerous level. Their behavior closely mimics a person with schizophrenia (Bramness et al, 2012; Robinson \& Becker, 1986).

Carlsson also discovered the link between dopamine levels and Parkinson's disease by manipulating dopamine levels. He dramatically depleted dopamine in an experiment, which lead his participants to exhibit many of the effects of Parkinson's disease (Carlsson \& Carlsson, 1990; Yaragani et al., 2010). This lead to him developing a treatment for Parkinson's disease which involves manipulating dopamine levels. This treatment is still used today (Iverson \& Iverson, 2007).

Because of Carlsson's work manipulating dopamine levels, other scholars have learned much more about the properties of dopamine, including its link to ADHD and impulsivity in general (Arnsten, 2006; Dalley \& Roiser, 2012; Solanto et al., 2012). People need the right amount of dopamine to function healthily (Buckholtz et al., 2010; Congdon et al., 2005). Carlsson's research suggests that 
manipulating dopamine is a powerful way to understand the effect of dopamine on behavior.

\section{The present study}

In the preliminary study, we saw that tDCS caused a reverse effect in impulsive people. I suspect that this was because elevated dopamine levels are associated with impulsivity (Buckholtz et al., 2010; Congdon et al., 2005; Dalley \& Roiser, 2012). In the dissertation study, I manipulated dopamine levels to see if I could intentionally cause a reverse effect of tDCS. This effect would help explain the interplay between impulsivity, dopamine, and brain stimulation.

\section{Methods of dissertation study}

\section{Participants}

To determine how many participants were needed for this study, I conducted an a priori power analysis. I based this analysis on the size of the interaction in the preliminary study. I considered using the effect size of caffeine on behavior in this analysis, but I chose not to because I hypothesized that the brain stimulation would interact with caffeine to most closely mirror the effect found in the preliminary study. In addition, I hypothesized that caffeine would have a reverse effect on people who also receive brain stimulation. There are no existing studies to my knowledge that study reverse effects associated with caffeine. For that reason, basing the analyses on the effect seen in the preliminary study seemed most logical.

I conducted an a priori power analysis in G*Power version 3.1 (see Erdfelder, Faul, \& Buchner, 1996 for a description of their $G^{*}$ Power program). 
The parameters included a linear regression model, an expected effect size of $\mathrm{f}^{2}$ $=0.04$, and three predictors (caffeine, brain stimulation, and their interaction). To achieve $80 \%$ power, I needed to test 190 people. I ultimately tested 202 participants to leave room for potential outliers. These participants were drawn from University of Kentucky's subject pool. Table 1 describes the demographics of the participants. The same safety criteria used in the preliminary study were used for this study.

All participants verified they were not regular drug users as part of the consent process. They let us know they had not had "any use of illicit drugs in the past 30 days" and "any history of weekly or more often drug use". This was compared to questions asked in a questionnaire in the study which asked how often they used marijuana, stimulants, and cocaine. The choices were never, occasionally, weekly, and daily.

\section{Procedures}

Upon completing the consent process, participants were randomly assigned to consume a caffeine pill containing $300 \mathrm{mg}$ of caffeine or a placebo pill. $300 \mathrm{mg}$ is a dose of caffeine that has been found to increase striatal dopamine receptor availability in humans by approximately $20 \%$ (Volkow et al., 2015). The caffeine takes 60 minutes to reach peak levels (Volkow et al., 2015).

After taking the caffeine or placebo, before it has had enough time to begin to work in a meaningful way, participants completed the UPPS scale used in the preliminary study. After completing the UPPS, which takes approximately 10 minutes, the participant completed additional questionnaires. These 
measured things such as how much caffeine they normally drink, their recreational drug use, how hungry they were, adherence to study guidelines, their height and weight, and other relevant variables to the study. This questionnaire took about 15 minutes. After this, the participants waited in the laboratory for about 15 minutes as the caffeine began to build in their bloodstream.

At the 40 minute mark, tDCS was attached to the participants. By random assignment, participants were exposed to either excitatory or sham tDCS over the right ventrolateral prefrontal cortex (rVLPFC). It took about 5 minutes to attach the tDCS. All attachment procedures will be identical to the ones used in the preliminary study.

After the electrodes were safely and comfortably attached, a 20 minute stimulation period will begin. Because tDCS takes about 10 minutes to become active in the brain (Riva et al., 2014), participants watched the Planet Earth neutral video, which was also used in the preliminary study. At the 10-minute mark, participants did depletion exercises for the remaining 10 minutes of stimulation as in the preliminary study. They performed the Crossing Out E's task and then the Stroop Task. After the 10 minutes had elapsed, participants stopped these exercises.

As in the preliminary study, the purpose of these depletion tasks was to mentally fatigue participants to avoid a ceiling effect on the dependent variable, which is the Stop Signal Task, also used in the preliminary study. After 20 minutes of stimulation, the tDCS ramped down and turned itself off, and the 
electrodes were removed from the participants. The tDCS continued to affect people for approximately 30 minutes (Filmer, Dux, and Mattingly, 2014). At this point, the caffeine was ingested 60 minutes prior, and had now reached peak levels in the body. The participants then received instructions for the Stop Signal Task and completed it. After the Stop Signal Task, the participants were debriefed.

\section{Planned analyses}

I hypothesized that people who received tDCS but no caffeine would have less errors on the Stop Signal Task than people who received sham stimulation and no caffeine. Likewise, I hypothesized that people who received sham stimulation and caffeine would have less errors on the Stop Signal Task than people who received sham stimulation and no caffeine. Finally, I expected a different effect for people who received both caffeine and brain stimulation. I thought people in this group would have more errors on the Stop Signal Task than people in any of the other three groups. I planned to use simple slopes tests and simple effects test to probe the hypothesized interaction between caffeine and brain stimulation.

To test these hypotheses, I used a regression analysis that tests for moderation. The predictors were brain stimulation, caffeine, and the interaction between brain stimulation and caffeine. These analyses were pre-registered on osf.io at osf.io/uqepn/register/5771ca429ad5a1020de2872e. This means I created a public, time-stamped document that shows what my hypotheses were 
before I began the study. Pre-registration helps a researcher demonstrate that their hypotheses were a priori.

The analyses that were not pre-registered are considered to be exploratory. This means they were not hypothesized a priori. Multiple comparisons are not corrected for in these analyses. The rationale for this is discussed in chapter four of this manuscript.

\section{Results}

When looking at the four conditions, there were not significant differences in error rates. People who received sham stimulation and the placebo had an average error rate of $50.32 \%(S D=14.81)$ on the Stop Signal Task. People who received tDCS and the placebo had an average error rate of $50.22 \%$ ( $S D=16.55)$. People who received sham stimulation and caffeine had an average error rate of $54.12 \%(S D=18.14)$. People who received tDCS and caffeine had an average error rate of $51.86 \%(S D=18.37)$.

There was no interaction between caffeine and tDCS on error rate on the Stop Signal Task, $B=-2.16, t(199)=-0.45, p=0.657, d=0.13$. There was no main effect of tDCS on error rate, $B=-0.10, t(199)=-0.03, p=0.977$. There was no main effect of caffeine on error rate, $B=3.80, t(199)=1.11, p=0.268$.

To test for the effectiveness of random assignment, I used one-way ANOVAs to see if there were differences among the four groups on MCQ scores and the five dimensions of impulsivity (positive urgency, negative urgency, lack of premeditation, lack of perseverance, and sensation-seeking). There was one significant difference among groups on lack of premeditation, $F(3,189)=2.74$, 
$p=0.045$. A Fisher's least squares difference test determined that the caffeine and sham stimulation group $(M=5.80, S D=1.49)$ was significantly lower on lack of premeditation than the placebo and tDCS group $(M=6.67, S D=2.09)$,

$M_{\text {difference }}=0.87, S E=0.39, p=0.028$.

\section{Exploratory results}

\section{Lack of premeditation.}

There was a significant interaction among tDCS, caffeine, and lack of premeditation, $B=7.27, t(196)=2.75, p=0.007, d=0.44$ (see Figure 4). To better understand the nature of this interaction, I examined the simple slopes of each of the four lines in Figure 4. In the condition with sham stimulation and the placebo, there was a significant positive slope of lack of premeditation on error rate, $B=2.74, t(196)=2.50, p=0.016$. In the condition with sham stimulation and caffeine, there was a marginal negative slope of lack of premeditation on error rate, $B=-3.35, t(196)=-1.87, p=0.068$. In the condition with tDCS and placebo, there was no significant relationship between lack of premeditation and error rate, $B=-1.17, t(196)=-1.11, p=0.27$. In the condition with tDCS and caffeine, there was no significant relationship between lack of premeditation and error rate, $B=0.10, t(196)=0.01, p=0.994$.

I also looked at simple effects in this model. First, I looked at the people who were high on lack of premeditation. In this model, there was a simple effect of tDCS, $B=23.24, t(196)=2.05, p=-.041$. There was also a simple effect of caffeine, $B=39.82, t(196)=3.12, p=0.002$. There was a significant interaction between tDCS and caffeine, $B=-44.99, t(196)=2.18, p=0.009$. To better 
understand the nature of that interaction, I tested simple slopes. For people high on lack of premeditation, in the anode condition, there was not a significant effect of caffeine in the simple slopes test. For people high on lack of premeditation, in the sham condition, there also was not a significant effect of caffeine in the simple slopes test. I also tested simple effects in this interaction. There were no significant simple effects for people high on lack of premeditation in the anode condition or the sham condition.

Next, I tested simple effects in the people who were low on lack of premeditation. There was a marginal simple effect of tDCS, $B=-8.95, t(196)=-$ $1.94, p=0.054$. There was also a marginal simple effect of caffeine, $B=-10.33$, $t(196)=-1.75, p=-.081$. There was a significant interaction between tDCS and caffeine, $B=14.85, t(196)=2.06, p=0.041$. To probe that interaction, I tested simple slopes. For people low on lack of premeditation, in the sham condition, there was a significant effect caffeine in the simple slopes test, $B=18.68$, $t(196)=2.95, p=0.007$. For people low on lack of premeditation, in the anode condition, there was not a significant effect of caffeine in the simple slopes test. I also tested simple effects in this interaction. For people low on lack of premeditation, in the sham condition, there was a significant simple effect of caffeine, $B=18.80, t(196)=2.38, p=0.023$. For people low on lack of premeditation, in the anode condition, there was not a significant simple effect of caffeine.

After that, I tested simple effects in the people who got anodal stimulation. There were no significant simple effects or interactions in this model. 
I also tested simple effects in the people who got sham stimulation. There was a significant simple effect of caffeine in this model, $B=40.27, t(196)=3.12$, $p=0.002$. There was also a significant simple effect of lack of premeditation, $B=2.78, t(196)=2.19, p=0.30$. There was a significant interaction between tDCS and lack of premeditation, $B=-6.17, t(196)=-2.93, p=0.004$. To probe this interaction, I first did a simple slopes test. Among people who got the sham stimulation, who got the placebo pill, there was a significant effect of lack of premeditation, $B=2.74, t(196)=2.50, p=0.016$. Among people who got sham stimulation, who got the caffeine pill, there was a marginal effect of lack of premeditation, $B=-3.35, t(196)=-1.87, p=0.068$. Next, I tested simple effects. There were no significant simple effects in this interaction.

Next, I tested simple effects in the people who got caffeine. There was no simple effect of tDCS in this model. There was a marginally significant effect of lack of premeditation, $B=-3.14, t(196)=-1.95, p=0.053$. There was not a significant interaction of tDCS and lack of premeditation.

Finally, I tested simple effects in the people who got the placebo. There were no significant simple effects or interactions in this model.

\section{Sensation-seeking.}

There was not a significant interaction among tDCS, caffeine, and sensation-seeking, $B=-0.05, t(196)=-0.03, p=0.980$. There were no significant main effects in this model.

Stimulant use. 
There was a significant 3-way interaction among tDCS, caffeine, and stimulant use, $B=27.26, t(196)=2.01, p=0.045, d=0.84$ (see Figure 5). The group with the highest error rate was people who used stimulants, received caffeine, and got tDCS had the highest error rate at $61 \%, 4 \%$ higher than any of the other groups. When combined with tDCS and caffeine, stimulant use was significantly maladaptive to performance on the Stop Signal Task. Frequencies about participant drug use can be found in Table 2.

To better understand the nature of this interaction, I examined the simple slopes of each of the four lines in Figure 5 . In the condition with sham stimulation and the placebo, there was no significant relationship between stimulant use and error rate, $B=1.82, t(196)=0.30, p=0.765$. In the condition with sham stimulation and caffeine, there was no significant relationship between stimulant use and error rate, $B=-5.42, t(196)=-0.65, p=0.52$. In the condition with tDCS and placebo, there was no significant relationship between stimulant use and error rate, $B=-$ 2.43, $t(196)=-0.67, p=0.504$. In the condition with tDCS and caffeine, there was a significant positive slope of stimulant use on error rate, $B=17.59, t(196)=2.10$, $p=0.041$.

I also looked at simple effects in this model. First, I looked at people who were stimulant users. There were no significant simple effects or interactions in this model. This could be driven by there being only 19 stimulant users in the study. This makes this model underpowered.

In addition, I looked at people who do not use stimulants. There were no significant simple effects in this model. However, there was a marginally 
significant interaction between tDCS and caffeine, $B=-16.76, t(196)=-1.93$, $p=0.056$. To better understand the nature of this interaction, I performed simple slopes tests. There were no significant simple slopes in this model. I also performed simple effects tests. There were no significant simple effects in this model.

Following that, I looked at the people who got anodal stimulation. There were no significant simple effects in this model. However, there was a significant interaction between caffeine and stimulant use, $B=19.75, t(196)=2.28, p=0.024$. To probe this interaction, I performed simple slopes tests. There were no significant simple slopes in this model. I also performed simple effects tests. There were no significant simple effects in this model.

Next, I looked at the people who got sham stimulation. There were no significant simple effects or interactions in this model.

After that, I looked at the people who got caffeine. There were no significant simple effects in this model. However, there was a significant interaction between tDCS and stimulant use, $B=22.06, t(196)=2.06, p=0.040$. To probe this interaction, I tested simple slopes. There were no significant simple slopes in this model. I also tested simple effects. There was not a significant simple effect of stimulant use among people who got caffeine and were in the sham stimulation condition. However, there was a significant simple effect of stimulant use among people who got caffeine and were in the anode stimulation condition, $B=17.36, t(196)=1.95, p=0.042$. 
Finally, I looked at the people who got the placebo. There were no significant simple effects or interactions in this model.

Hunger.

There was a significant interaction among tDCS, caffeine, and hunger, $B=6.18, t(196)=2.16, p=0.032$ (see Figure 6 ). There was a main effect of caffeine in this model, $B=20.56, t(196)=2.38, p=0.018$. There was also a significant interaction between tDCS and caffeine when controlling for hunger, $B=-26.24$, $t(196)=-2.25, p=0.026, d=0.35$.

To better understand the nature of this interaction, I examined the simple slopes of each of the four lines in Figure 6 . In the condition with sham stimulation and placebo, there was no significant relationship between hunger and error rate, $B=1.86, t(196)=1.58, p=0.12$. In the condition with sham stimulation and caffeine, there was no significant relationship between hunger and error rate, $B=-2.48$, $t(196)=-1.48, p=0.147$. In the condition with tDCS and placebo, there was no significant relationship between hunger and error rate, $B=1.52, t(196)=1.11$, $p=0.275$. In the condition with tDCS and caffeine, there was a significant positive relationship of hunger on error rate, $B=3.35, t=2.21, p=0.032$.

I also looked at simple effects in this model. First, I looked at the people who were hungry (1 SD above the mean on hunger). There was not a significant simple effect of tDCS in this model. There was a significant simple effect of caffeine, $B=13.16, t(196)=2.37, p=0.019$. There was a significant interaction between tDCS and caffeine, $B=-15.73, t(196)=-2.10, p=0.038$. To probe this interaction, I first tested simple slopes. There were no significant simple slopes in 
this model. Next, I tested simple effects. There were no significant simple effects in this model.

Additionally, I looked at the people who were not hungry (1 SD below the mean on hunger). There was not a significant simple effect of tDCS in this model. There was a significant simple effect of caffeine, $B=27.95, t(196)=2.34, p=0.020$. To probe this interaction, I first tested simple slopes. There were no significant simple slopes in this model. Next, I tested simple effects. There were no significant simple effects in this model.

Following that, I looked at the people who got anodal stimulation. There were no significant simple effects or interactions in this model.

After that, I looked at the people who got sham stimulation. There was a simple effect of caffeine in this model, $B=20.81, t(196)=2.29, p=0.018$. There was not a simple effect of hunger and no significant interaction in this model.

As a next step, I looked at the people who got caffeine. There was a simple effect of tDCS in this model, $B=-23.28, t(196)=-2.77, p=0.006$. There was no simple effect of hunger. There was a significant interaction between tDCS and hunger, $B=5.62, t(196)=2.75, p=0.007$. To probe this interaction, I performed a simple slopes test. Among people who got caffeine and sham stimulation, there was no significant effect of hunger. Among people who got caffeine and anodal stimulation, there was a significant effect of hunger, $B=2.25, t(196)=2.21$, $p=0.032$. Next, I performed a simple effects test. Among people who got caffeine and sham stimulation, there was not a significant simple effect of hunger. Among 
people who got caffeine and anodal stimulation, there was a significant simple effect of hunger, $B=3.30, t(196)=2.18), p=0.032$.

Finally, I looked at people who got the placebo. There were no significant simple effects or interactions in this model.

Marijuana.

There was no significant interaction among tDCS, caffeine, and marijuana use, $B=4.13, t(196)=0.55, p=0.585$. There were no significant main effects in this model.

Eating before the study.

There was no significant interaction among tDCS, caffeine, and following the study rule of abstaining from food for four hours before the study, $B=12.91$, $t(196)=0.848, p=0.397$. In this model, there was a main effect of caffeine, $B=22.89, t(196)=2.10, p=0.037$. There was a marginal but nonsignificant interaction between caffeine and abstaining from food for four hours before the study, $B=-21.04, t(196)=-1.83, p=0.069$.

Weight.

There was not a significant interaction among tDCS, caffeine, and weight, $B=-0.19, t(196)=-1.12, p=0.264$. There were no significant main effects in this model.

Gender.

There was not a significant interaction among tDCS, caffeine, and gender, $B=-3.69, t(195)=-0.33, p=0.744$. There were no significant main effects in this model. This analysis only included men and women and excluded people of 
other gender identities $(n=1)$, because the sample size of people of other genders was too small to be appropriate for this type of analysis.

Drug use overall.

A logistic regression was used to see if there were a significantly different amount of drug users in each of the four groups used in the primary analysis in this study: placebo and sham, placebo and tDCS, caffeine and sham, and caffeine and tDCS. There was no significant difference on how many drug users there were in this group. For the tDCS category, $B=0.11, X^{2}=0.011, p=0.972$. For the caffeine category, $B=0.48, x^{2}=2.51, p=0.113$.

I ran an additional analysis examining the interaction between tDCS and caffeine in only participants who never use marijuana or stimulants (the only drugs asked about in the survey). There were no significant interactions and no main effects in this model, $B=-3.94, t(133)=-0.59, p=0.577$.

Model controlling for significant interactions.

There were three variables in this study that significantly interacted with tDCS and caffeine: lack of premeditation, stimulant use, and hunger. I ran a model about how tDCS and caffeine interact with error rate on the Stop Signal Task controlling for these factors. There was not a significant interaction between tDCS and caffeine even when controlling for these factors, $B=-1.34, t(195)=-0.28$, $p=0.779$. 
Table 2, Demographics of the tDCS and Caffeine Study.

\begin{tabular}{|l|l|l|l|}
\hline Age & Mean & SD & Range \\
\hline & 19.1 years old & 1.1 years & $18-24$ years old \\
\hline Race & Asian & $6 \%$ \\
\hline & Biracial & $6.5 \%$ \\
\hline & Black & $12 \%$ \\
\hline & Hispanic & $6 \%$ \\
\hline & Other race & $1 \%$ \\
\hline Gender & White & $68 \%$ \\
\hline & Man & $26.6 \%$ \\
\hline & Woman & $72.9 \%$ \\
\hline $\begin{array}{l}\text { Sexual } \\
\text { orientation }\end{array}$ & Other & $0.5 \%$ \\
\hline & Heterosexual & $91.5 \%$ \\
\hline & Sexual minority & $8.5 \%$ \\
\hline
\end{tabular}

Demographic information about participants in study 2 . 
Table 3, Recreational Drug Use in the tDCS and Caffeine Study.

\begin{tabular}{|l|l|l|l|l|}
\hline & Never & Occasionally & Weekly & Daily \\
\hline Marijuana & $71.0 \%$ & $24.5 \%$ & $1.5 \%$ & $3.0 \%$ \\
\hline $\begin{array}{l}\text { ADHD } \\
\text { medication }\end{array}$ & $91.0 \%$ & $8.5 \%$ & $0.5 \%$ & $0 \%$ \\
\hline Cocaine & $98.0 \%$ & $1.5 \%$ & $0.5 \%$ & $0 \%$ \\
\hline
\end{tabular}

Recreational drug use in participants. 
Figure 3, tDCS and Caffeine's Effects on Error Rate.

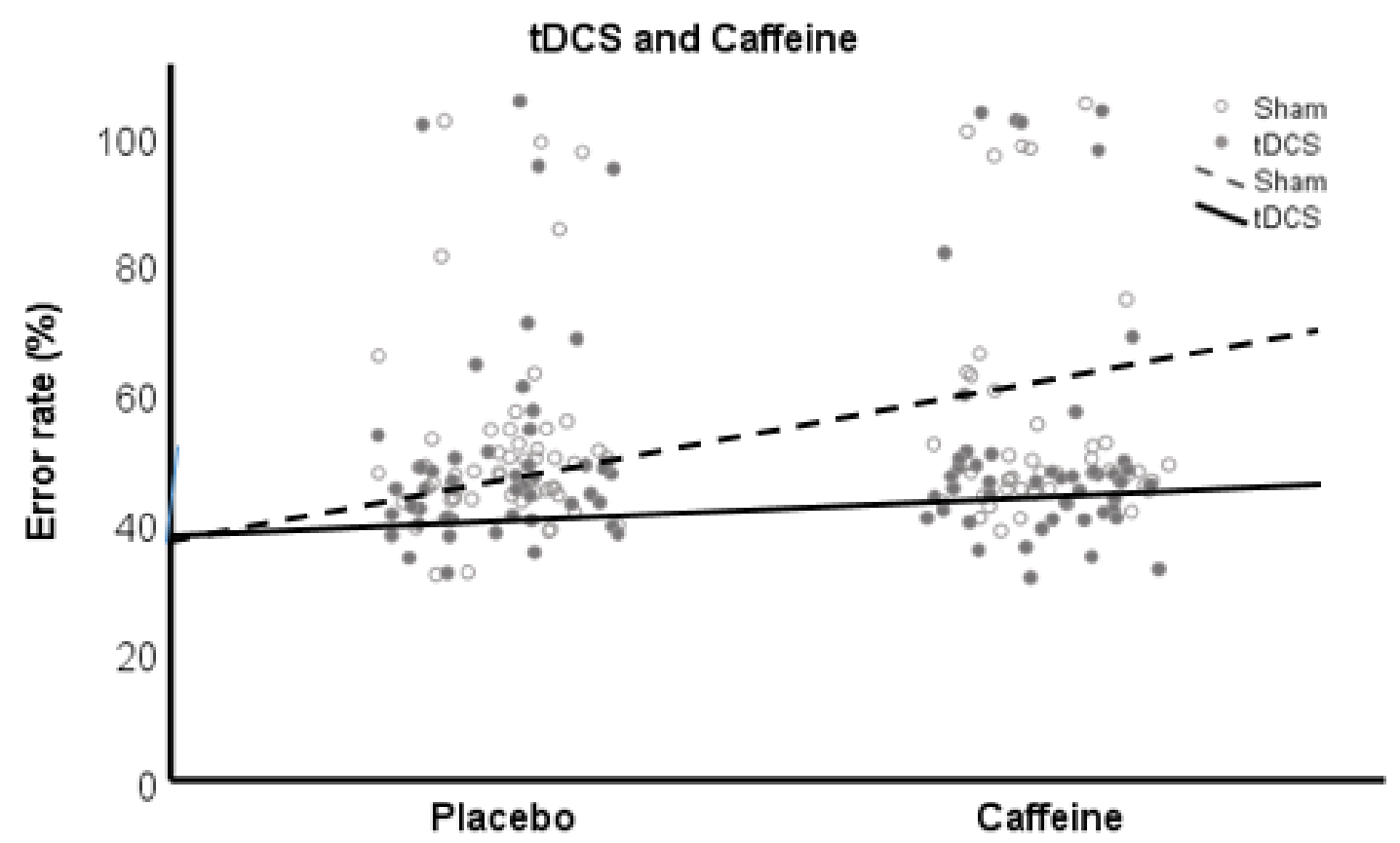

tDCS and caffeine alone or together did not have any significant effects on error rate on the Stop Signal Task. 
Figure 4, Lack of Premeditation and Error Rate.

A.

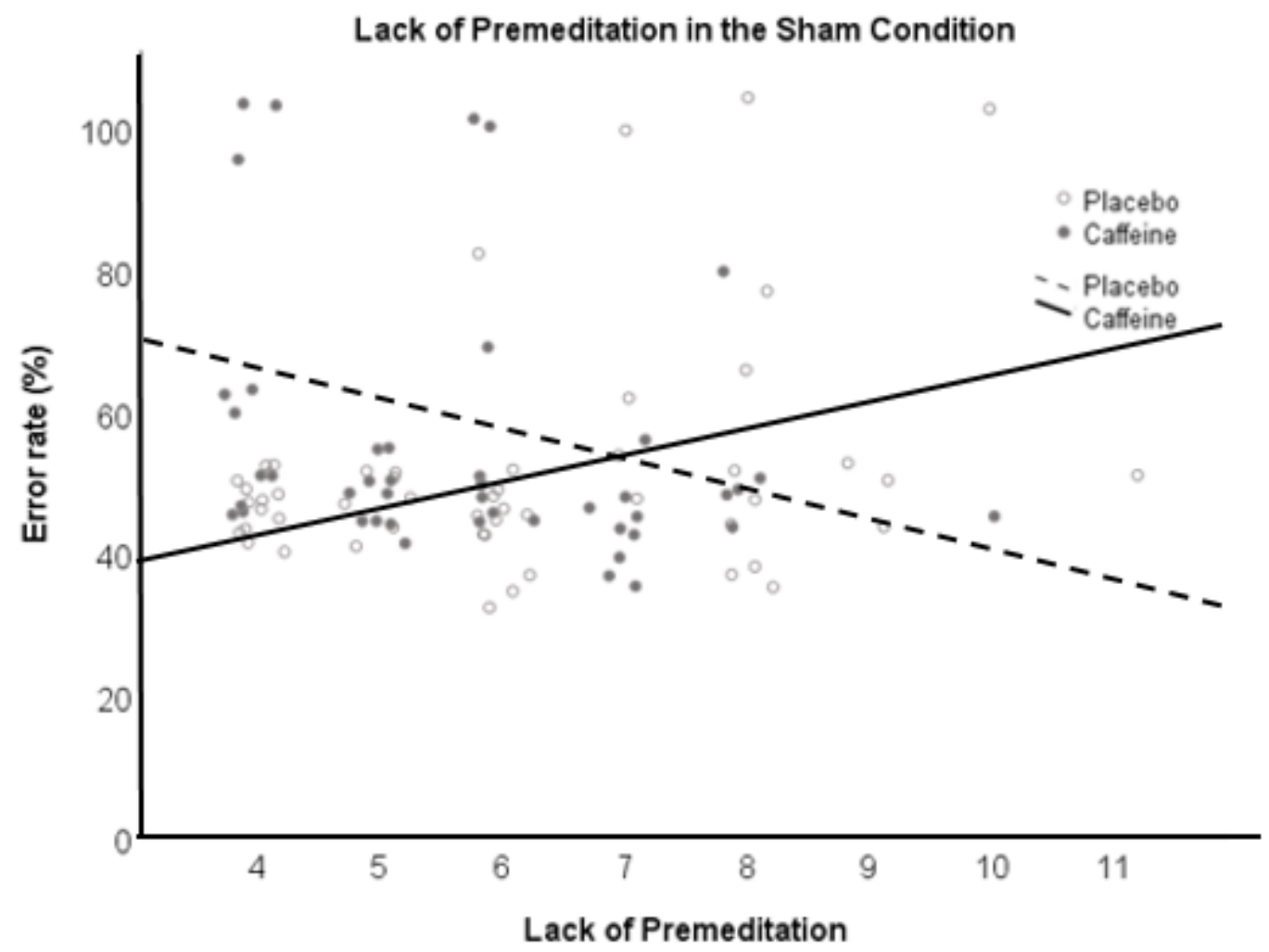

Figure description following B. panel. 
Figure 4, Lack of Premeditation and Error Rate.

B.

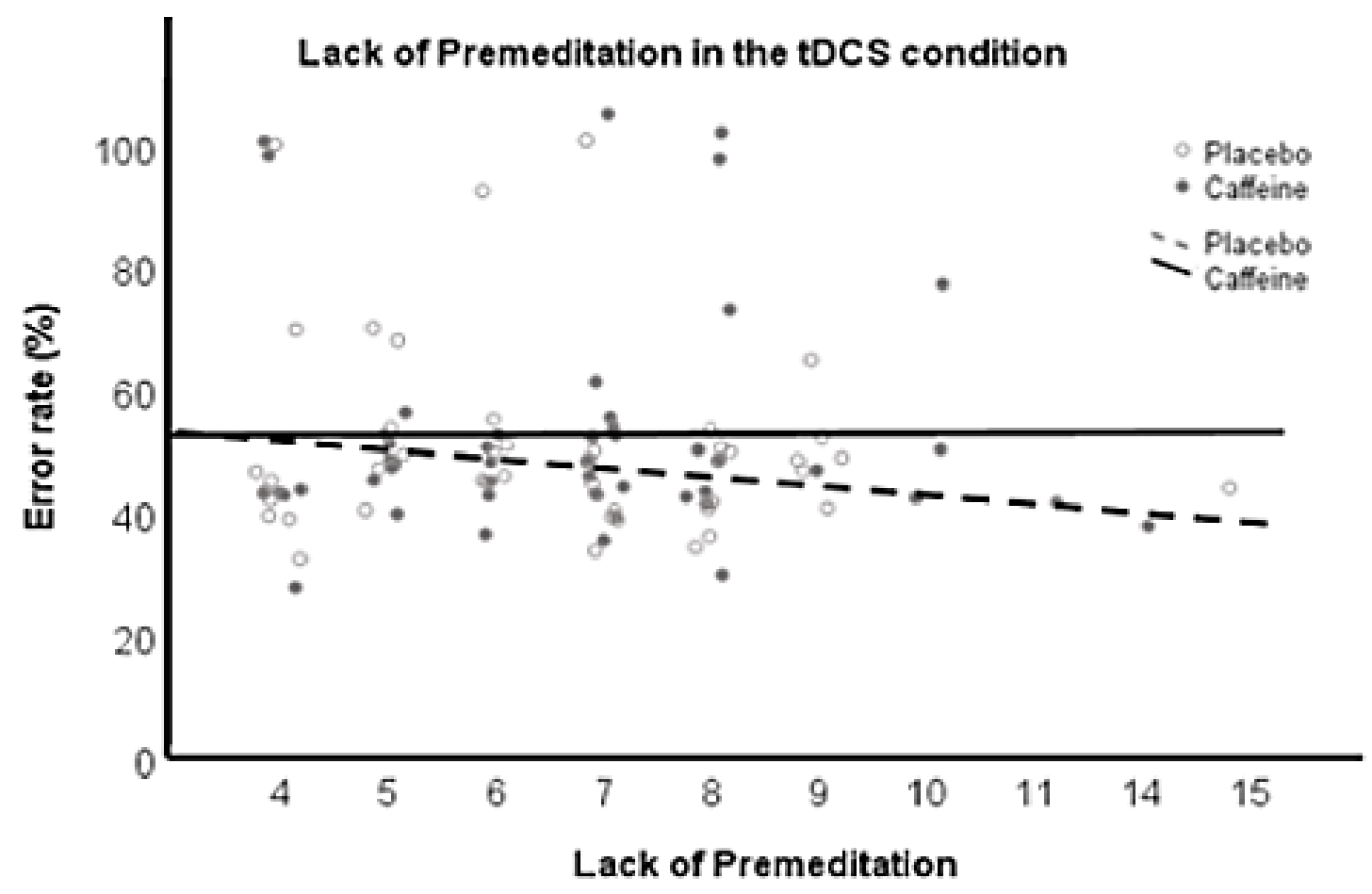

tDCS, caffeine, and lack of premeditation had a significant 3-way interaction, $B=7.27, t(196)=2.75, p=0.007$. People receiving caffeine who were also low on lack of premeditation and in the sham condition had the highest error rate.

People receiving the placebo who were also low on lack of premeditation and in the sham condition had the lowest error rate. 
Figure 5, Stimulant Use and Error Rate.

A.

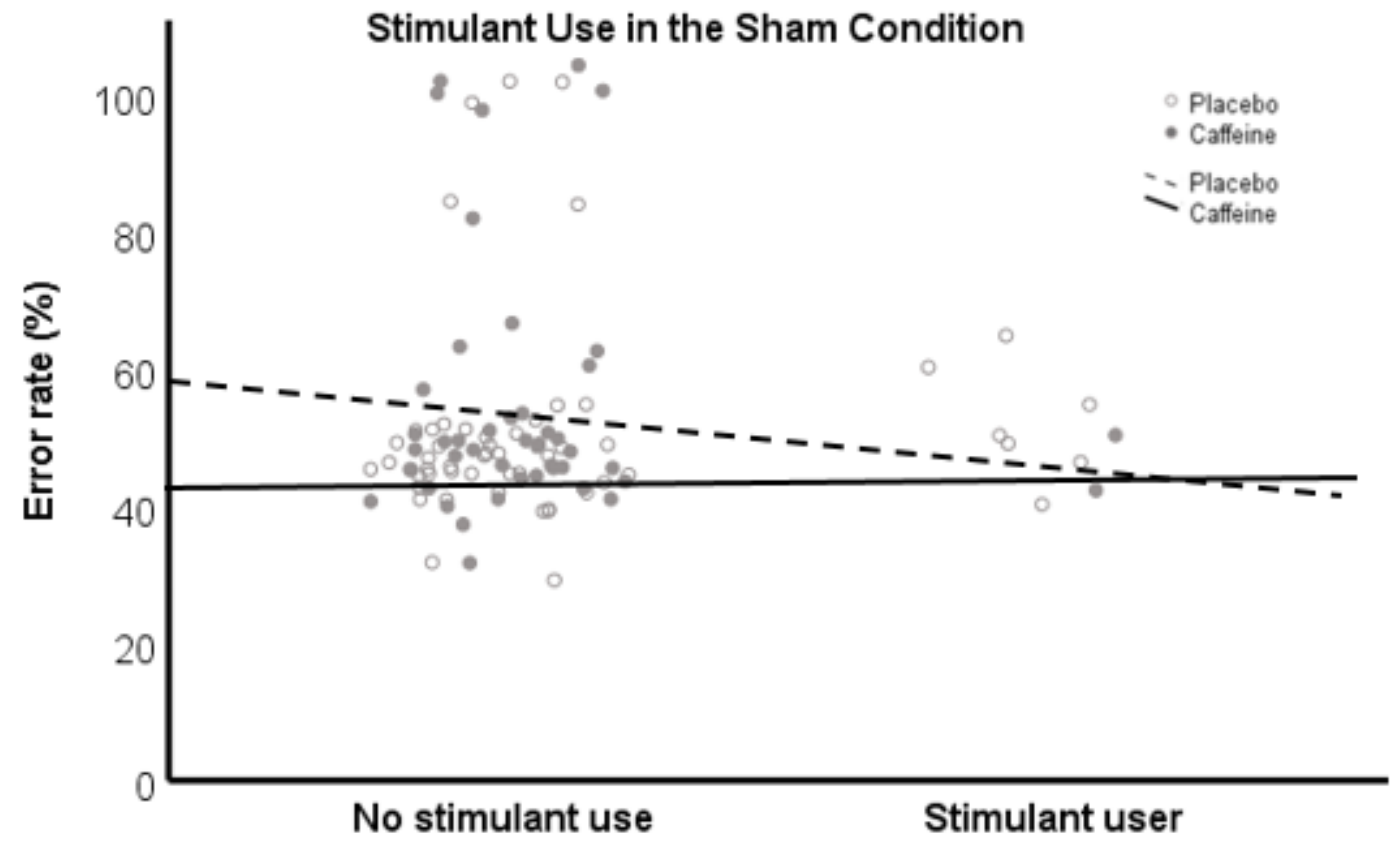

Figure description following B. panel. 
Figure 5, Stimulant Use and Error Rate.

B.

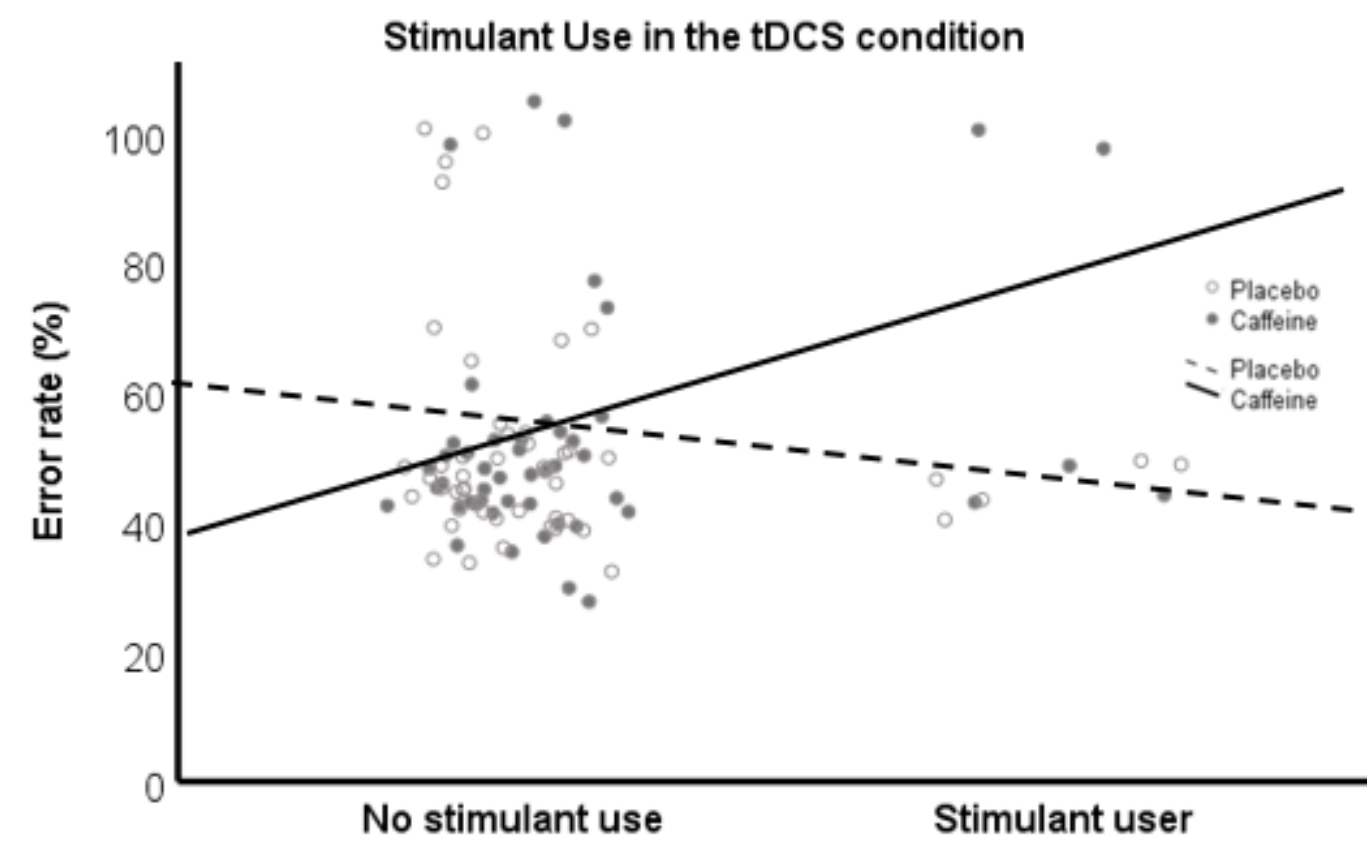

Significant 3 way interaction among tDCS, caffeine, and use of stimulants, as defined by use of cocaine, recreational amphetamines, or both. $10 \%$ of the sample used stimulants $(n=19) .7$ of them received sham stimulation and the placebo. 2 of them received sham stimulation and caffeine. 5 of them received tDCS and the placebo. 5 of them received tDCS and caffeine. 
Figure 6, Hunger and Error Rate.

A.

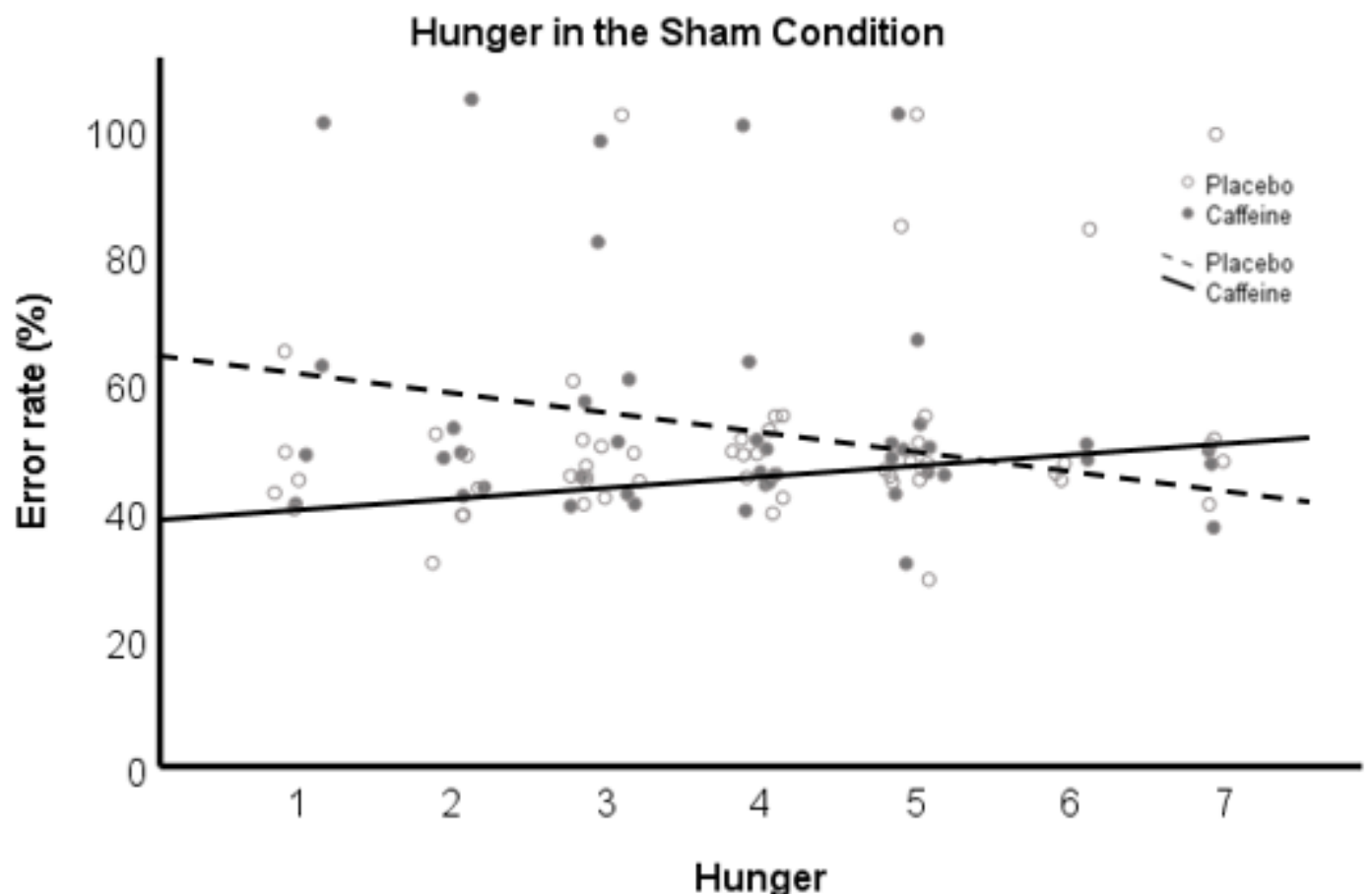

Figure description following B. panel. 
Figure 6, Hunger and Error Rate.

B.

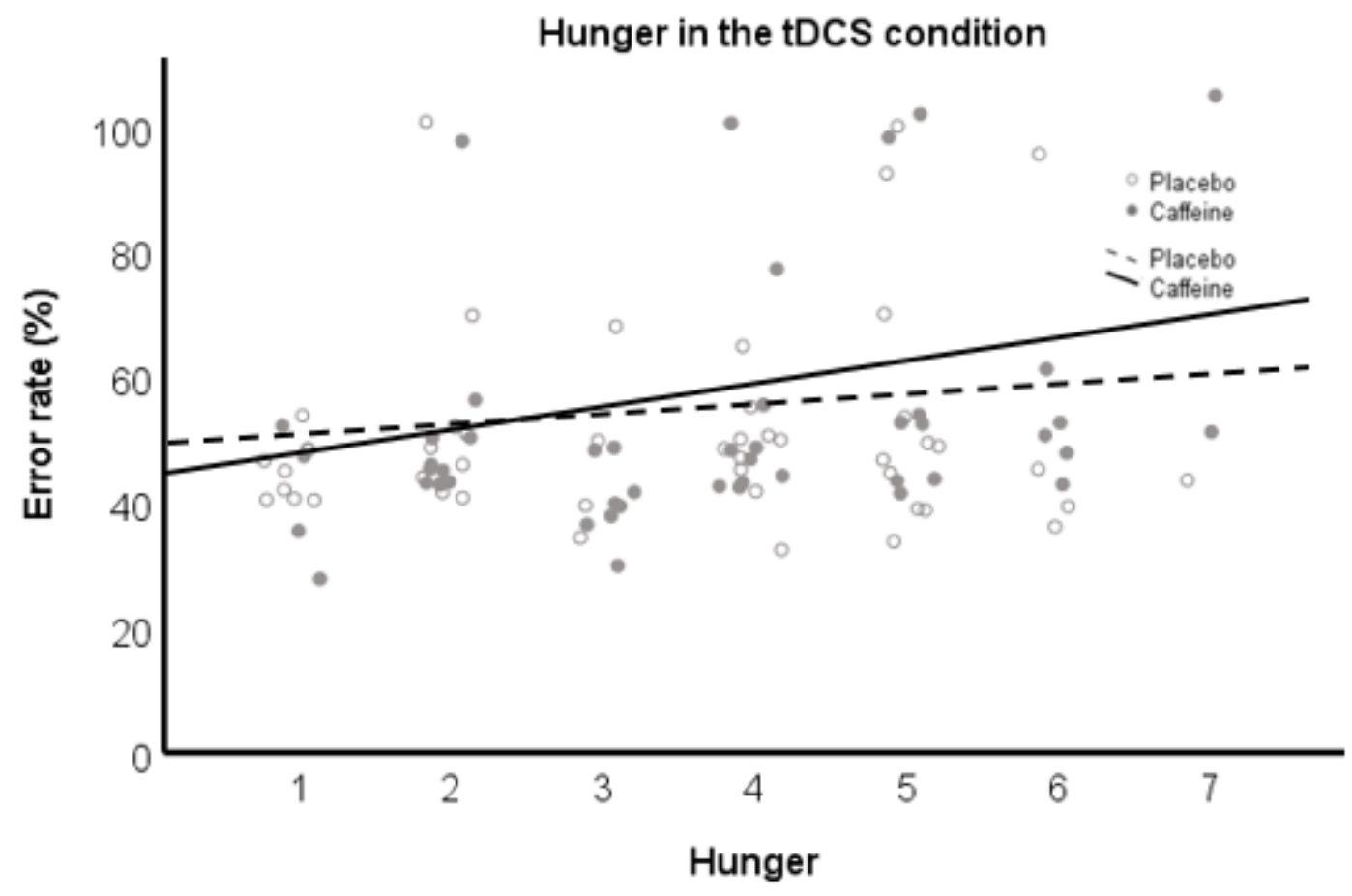

Significant 3 way interaction among tDCS, caffeine, and hunger. Not hungry means 1 standard deviation below the mean on hunger. Hungry means 1 standard deviation above the mean on hunger. 


\section{Chapter 4}

In the preliminary study, we observed the interplay between trait levels of impulsivity and error rate on the Stop Signal Task. Trait levels of impulsivity were associated with an increased error rate in people who also received tDCS. I hypothesized that this effect occurred because of the high levels of dopamine associated with both impulsivity and reverse effects of tDCS. The dissertation study manipulated dopamine levels in order to replicate and extend the findings of the preliminary study.

There was no effect of brain stimulation and caffeine on error rate in the

Stop Signal Task as predicted. This has an array of implications for this two study package. Perhaps dopamine levels were not raised enough by caffeine to cause the hypothesized reverse effect. Likewise, perhaps personality is driving the effect seen in study 1 rather than the dopamine associated with impulsive personalities.

Another reason we see different results in study 1 and study 2 could be due to a group level personality difference among participants across the two studies. There was a significant difference between the two groups on their scores on the Monetary Choice Questionnaire, a measure of impulsivity and delay discounting (Kirby, 1996). People in study 2 were significantly more impulsive than people in study $1, t(314)=2.20, p=0.029$. Since the dependent 
variable was also a measure of impulsive behavior, this difference could be a key factor in the different results seen in these two studies.

An additional reason we see different results in study 1 and study 2 could be due to variability in neurotransmitter levels in chemicals other than dopamine. Serotonin is known to potentiate tDCS (Kuo et al., 2016), and GABA has been associated with reverse effects of tDCS (McLaren, Nissim, \& Woods, 2018; Monte-Silva et al., 2010). Therefore, while the present study focused on the interaction between dopamine levels and tDCS, other neurotransmitters almost certainly are interacting with tDCS as well.

Lack of premeditation.

There was a significant interaction among tDCS, caffeine, and lack of premeditation (see Figure 4). Generally speaking, caffeine was helpful to people who were high on lack of premeditation, but maladaptive to people who were low on lack of premeditation. One potential reason for this is because people high on lack of premeditation sometimes have dopamine levels that are too low. This relates to people with ADHD, who are also high on lack of premeditation, being treated by stimulants that adaptively increase their dopamine levels. However, people low on lack of premeditation do not have the same problems with baseline dopamine levels as their more impulsive counterparts. In these cases, the caffeine may be maladaptively raising their dopamine levels to be too high, causing them to become more impulsive and make mistakes on the task.

Another way to think of this phenomenon is thinking of caffeine as being somewhat like an amphetamine, in that both amphetamines and caffeine raise 
dopamine levels. This is helpful to people who have dopamine levels that are too low. This is maladaptive to people who already have healthy dopamine levels.

tDCS had a similar effect as caffeine with regard to it differently affecting people high on lack of premeditation and people low on lack of premeditation.

tDCS is known to raise dopamine levels (Tanaka et al., 2013, Strafella, 2001). When people high on lack of premeditation got tDCS, their potentially low baseline levels of dopamine were adaptively raised. When people low on lack of premeditation got tDCS, their already appropriate dopamine levels were maladaptively raised. In this way, tDCS is also acting like a stimulant. Because both caffeine and tDCS raise dopamine levels, it is not surprising that they had a similar effect on people who were high on lack of premeditation and a similar effect of people who were low in lack of premeditation.

When tDCS and caffeine were combined, there was not a significant difference in errors on the Stop Signal Task as compared to receiving just tDCS. This suggests that the effects of tDCS and caffeine may not be purely additive. Instead, having just tDCS or just caffeine seems to have almost the same effect as having both.

An additional factor in this effect could be the significantly lower scores on lack of premeditation in the sham and caffeine group as compared to the tDCS and placebo group. Caffeine was generally maladaptive for people low on lack of premeditation, and this group had a larger number of people who were one standard deviation below the mean on lack of premeditation. This could be one reason why the error rate was elevated in this group. 


\section{Stimulants.}

We found a reverse effect of tDCS and caffeine in our exploratory analyses (see Figure 5). This relates to the idea of too much of a good thing. Being stimulated by tDCS, caffeine, and being a recreational cocaine or Adderall user was found to be maladaptive to error rate. All three of these increase dopamine, and too much dopamine is linked to impulsive behavior (Buckholtz et al., 2010; Dalley \& Roiser, 2012).

This begets the question of why cocaine and amphetamines are causing this effect when presumably the participants are not using them during the time of the study. One possibility is byproducts of the stimulants remaining in the participants' bodies. If they had used up to a couple days before the experiment, this is a distinct possibility (Nestler et al., 2005; White et al., 1995).

Another possibility is that the participants have experienced lasting brain changes from their recreational stimulant use. This includes changes in the glutamate system, which is important for learning and memory as well as longterm potentiation (Baker et al, 2003; Conrad et al., 2010). Chronic stimulant use also affects the orbitofrontal cortex, which is important for judgment and decision making (Kiyatin et al., 2012; Prisciandaro et al., 2014).

A third possibility is that the different effect of tDCS and caffeine on recreational stimulant is not driven primarily by the stimulants themselves. Rather, people who choose to use drugs such as Adderall and cocaine recreationally may have different personalities than others in the experiment. Evidence shows that stimulant users are likely to be aggressive and develop 
personality disorders (Gillespie et al., 2018; Moeller et al., 2002; Weiss et al., 1993). The neurochemistry related to these problems could also be driving this effect.

\section{Hunger.}

When people received sham stimulation and caffeine, and were also hungry, there was a significantly lower error rate than when they were not hungry. Hunger increases the bioavailability of caffeine (Brachtel \& Richter, 1988). Likewise, lack of hunger would stand to decrease the bioavailability of caffeine, making it as if the person had taken a smaller dose of caffeine.

When tDCS and caffeine were combined, the opposite finding occurred. In this case, the not hungry people did significantly worse than the hungry people. One theory is that the tDCS is tempering the maladaptive effects of caffeine. The second part of this theory is that a lower dose of caffeine is more adaptive than a very high dose, like the $300 \mathrm{mg}$ used in this study.

Think of the hungry person as a person who had a higher dose of caffeine because of their empty stomach. Think of the not hungry person as a person who had a lower dose of caffeine because of their full stomach. The hungry person, an analog for a high dose of caffeine, does well with just caffeine. However, when adding tDCS to this mix, their dopamine level may become maladaptively high, leading to an elevated error rate. Likewise, the not hungry person, an analog for a low dose of caffeine, does poorly with just caffeine. However, when adding tDCS to this mix, their dopamine level may become adaptively elevated, leading to a decreased error rate. 
To further test this theory, I would need to combine tDCS and different doses of caffeine. I would also need to have better control over what the participants were eating before the study. All participants said during the consent process that they abstained from food for four hours before the study. Otherwise, we would not have moved forward with the experiment. However, $12 \%$ of them went on to admit they did not follow these instructions during the private survey in the experiment. A hospital setting would be an ideal place to use a variety of caffeine doses because the hospital could both better control food intake before the study as well as treat adverse effects that could result from higher doses of caffeine than were used in the present study.

\section{Limitations and future directions}

One limitation of this study relates to the relatively modest effect of caffeine on dopamine. A dose of $300 \mathrm{mg}$ of caffeine only raises dopamine levels by approximately $20 \%$ (Solinas et al., 2002). It would be more direct to study this paradigm with a drug such as amphetamines to further raise dopamine levels.

Another limitation is that we did not measure dopamine levels. An extension of this work would be to do an exact replication of the preliminary study but collect dopamine levels at baseline as well as after stimulation. This would answer two questions: to what extent are dopamine levels in impulsive people elevated, and what is the magnitude that tDCS further increases dopamine levels?

Use of the Stop Signal Task is also a limitation in these studies, as it is only one conceptualization of impulsivity that relies heavily on inability to inhibit a 
prepotent response. An alternative measure of impulsivity that could be used in conceptual replications of this study would be a delay of gratification task. Delay of gratification tasks measure impulsivity in a way that avoid a confound with attention span (Nichols \& Waschbusch, 2004).

An additional limitation is that I did not correct for multiple comparisons in the exploratory analyses. Using a correction method such as the Bonferroni method on these analyses would have perhaps been overly conservative for the number of tests I conducted. In his paper 'Why we (usually) don't have to worry about correcting for multiple comparisons", Gelman (2012) describes flaws in correcting for multiple comparisons. Most notably, the Bonferroni test decreases type I errors but can greatly increase type II errors. A caveat of exploratory (nona priori) analyses is that they are not confirmatory. A prior hypothesis is needed in order to avoid violating the rules of null hypothesis testing. Therefore, my exploratory analyses merely suggest directions for future research and do not confirm a phenomenon.

$31 \%$ of the participants said they smoke marijuana at least occasionally. However, only $4.5 \%$ of them smoked it on a weekly or daily basis. Marijuana has a much longer half-life than almost all other recreational drugs (Johansson \& Halldin, 1989). The interactive effects of brain stimulation and marijuana are unknown. It is also possible that participants are underreporting their marijuana use, and even more than $31 \%$ of the sample is using marijuana. The exact definition of what occasional drug use means to the individuals in our research is not known. We do not know if most of them use a couple of times a month or a 
couple times per year. Because of this, a narrower study might only include people who do not smoke marijuana as determine by a confidential drug test to avoid this potential interactive effect. While we did not find significant effects of marijuana use in our analyses, further research could examine the relationship between marijuana and brain stimulation.

A final limitation is the dose of tDCS used. Perhaps a dose of $1.5 \mathrm{~mA}$ is too subtle to cause the hypothesized interaction, especially if marijuana use in some participants is decreasing the efficacy of tDCS. People used to only use tDCS doses on 1-2 mA, but very recently, people have begun experimenting with

doses of $3 \mathrm{~mA}$ and $4 \mathrm{~mA}$ (Gebodh et al., 2019; Nikolin et al., 2019). A follow up study could replicate the dissertation study with doses of $1 \mathrm{~mA}, 2 \mathrm{~mA}, 3 \mathrm{~mA}$, and $4 \mathrm{~mA}$ to see if this is a dose-dependent effect.

\section{Concluding remarks}

tDCS does not always work in the intended direction. The preliminary study shows tDCS having a paradoxical effect on people with impulsive personalities, which is related to dopamine levels in the brain. In study 2 , however, increasing dopamine levels did not result in the hypothesized reverse effect. This suggests more work needs to be done about when and why tDCS causes reverse effects.

tDCS is similar to a drug in that it affects different people in different ways. tDCS is not a universal remedy. It can cause decreased performance in certain individuals as seen in the preliminary study. The extent to which this is related to individual differences in dopamine levels remains an open question. 
Failure to inhibit is a problem that plagues a variety of people, especially police officers and military personnel who have to make life or death decisions in a time crunch. The military is experimenting with using tDCS to increase performance, but these two studies suggest it is possible for this to backfire. tDCS can cause deleterious reverse effects in certain individuals and should be used with this potential side effect in mind. 


\section{References}

Aboitiz, Francisco, et al. (2014). Irrelevant stimulus processing in ADHD: catecholamine dynamics and attentional networks. Frontiers in psychology, 5, 183.

Acquas, E., Tanda, G., \& Di Chiara, G. (2002). Differential effects of caffeine on adopamine and acetylcholine transmission in brain areas of drug-naive and caffeine-pretreated rats. Neuropsychopharmacology, 27(2), 182.

Alsene, K., Deckert, J., Sand, P., \& de Wit, H. (2003). Association between A 2a receptor gene polymorphisms and caffeine-induced anxiety. Neuropsychopharmacology, 28(9), 1694.

Aman, C. J., Roberts Jr, R. J., \& Pennington, B. F. (1998). A neuropsychological examination of the underlying deficit in attention deficit hyperactivity disorder: Frontal lobe versus right parietal lobe theories. Developmental psychology, 34(5), 956.

Andersen, I. M., Kaczmarska, J., McGrew, S. G., \& Malow, B. A. (2008).

Melatonin for insomnia in children with autism spectrum disorders. Journal of child neurology, 23(5), 482-485.

Arnsten, A. F. (2006). Stimulants: the therapeutic actions in ADHD. Neuropsychopharmacology 31, 2376-2383.

Arvanitis, L. A., \& Miller, B. G. (1997). Multiple fixed doses of "Seroquel"(quetiapine) in patients with acute exacerbation of schizophrenia: a comparison with haloperidol and placebo. Biological psychiatry, 42(4), 233-246. 
Baker, D. A., McFarland, K., Lake, R. W., Shen, H., Tang, X. C., Toda, S., \& Kalivas, P. W. (2003). Neuroadaptations in cystine-glutamate exchange underlie cocaine relapse. Nature neuroscience, 6(7), 743.

Bari, A., \& Robbins, T. W. (2013). Inhibition and impulsivity: behavioral and neural basis of response control. Progress in neurobiology, 108, 44-79.

Barratt, E. S., Stanford, M. S., Kent, T. A., \& Alan, F. (1997). Neuropsychological and cognitive psychophysiological substrates of impulsive aggression. Biological psychiatry, 41(10), 1045-1061.

Basar, K., Sesia, T., Groenewegen, H., Steinbusch, H. W., Visser-Vandewalle, V., \& Temel, Y. (2010). Nucleus accumbens and impulsivity. Progress in neurobiology, 92(4), 533-557.

Bechara, A., Damasio, A. R., Damasio, H., \& Anderson, S. W. (1994). Insensitivity to future consequences following damage to human prefrontal cortex. Cognition, 50(1-3), 7-15.

Bell \& DeWall (in press). A meta-analysis of the effects of transcranial direct current stimulation to the prefrontal cortex on multiple realms of social behavior. Social

Cognitive and Affective Neuroscience, nsy069.

Bell \& DeWall (in preparation). The effects of transcranial direct current stimulation and glucose on impulsivity.

Bell \& DeWall (under review). The effects of transcranial direct current stimulation and mental fatigue on motivation. 
Bennabi, D., Nicolier, M., Monnin, J., Tio, G., Pazart, L., Vandel, P., \& Haffen, E. (2015). Pilot study of feasibility of the effect of treatment with tDCS in patients suffering from treatment-resistant depression treated with escitalopram. Clinical Neurophysiology, 126(6), 1185-1189.

Benninger, D. H., Lomarev, M., Lopez, G., Wassermann, E. M., Li, X., Considine, E., \& Hallett, M. (2010). Transcranial direct current stimulation for the treatment of Parkinson's disease. Journal of Neurology, Neurosurgery \& Psychiatry, 81(10), 1105-1111.

Bergh, C., Eklund, T., Södersten, P., \& Nordin, C. (1997). Altered dopamine function in pathological gambling. Psychological medicine, 27(2), 473-475.

Boeve, B. F., Silber, M. H., \& Ferman, T. J. (2003). Melatonin for treatment of REM sleep behavior disorder in neurologic disorders: results in 14 patients. Sleep medicine, 4(4), 281-284.

Boggio, P. S., Ferrucci, R., Rigonatti, S. P., Covre, P., Nitsche, M., PascualLeone, A., \& Fregni, F. (2006). Effects of transcranial direct current stimulation on working memory in patients with Parkinson's disease. Journal of the neurological sciences, 249(1), 31-38.

Boye, S. M., Grant, R. J., \& Clarke, P. B. (2001). Disruption of dopaminergic neurotransmission in nucleus accumbens core inhibits the locomotor stimulant effects of nicotine and D-amphetamine in rats. Neuropharmacology, 40(6), 792-805.

Brachtel, D., \& Richter, E. (1988). Effect of altered gastric emptying on caffeine absorption. Zeitschrift fur Gastroenterologie, 26(5), 245-251. 
Bramness, J. G., Gundersen, Ø. H., Guterstam, J., Rognli, E. B., Konstenius, M., Løberg, E. M., ... \& Franck, J. (2012). Amphetamine-induced psychosis-a separate diagnostic entity or primary psychosis triggered in the vulnerable?. BMC psychiatry, 12(1), 221.

Brunoni, A. R., Nitsche, M. A., Bolognini, N., Bikson, M., Wagner, T., Merabet, L., ... \& Ferrucci, R. (2012). Clinical research with transcranial direct current stimulation (tDCS): challenges and future directions. Brain Stimulation: Basic, Translational, and Clinical Research in Neuromodulation, 5(3), 175195.

Buckholtz, J. W., Treadway, M. T., Cowan, R. L., Woodward, N. D., Li, R., Ansari, M. S., ... \& Kessler, R. M. (2010). Dopaminergic network differences in human impulsivity. Science, 329(5991), 532-532.

Carden, S. W., Holtzman, N. S., \& Strube, M. J. (2017). CAHOST: An excel workbook for facilitating the Johnson-Neyman technique for two-way interactions in multiple regression. Frontiers in psychology, 8, 1293.

Carlsson, A. (1988). The current status of the dopamine hypothesis of schizophrenia. Neuropsychopharmacology.

Carlsson, M., \& Carlsson, A. (1990). Interactions between glutamatergic and monoaminergic systems within the basal ganglia-implications for schizophrenia and Parkinson's disease. Trends in neurosciences, 13(7), 272-276. 
Carlsson, A., \& Lindqvist, M. (1963). Effect of chlorpromazine or haloperidol on formation of 3-methoxytyramine and normetanephrine in mouse brain. Acta pharmacologica et toxicologica, 20(2), 140-144.

Carlsson, A., \& Waldeck, B. (1958). A fluorimetric method for the determination of dopamine (3-hydroxytyramine.). Acta physiologica scandinavica, 44(34), 293-298.

Carvalho, R. C., Silva, R. H., Abılio, V. C., Barbosa, P. N., \& Frussa-Filho, R. (2003). Antidyskinetic effects of risperidone on animal models of tardive dyskinesia in mice. Brain research bulletin, 60(1-2), 115-124.

Cauli, O., \& Morelli, M. (2005). Caffeine and the dopaminergic system. Behavioural pharmacology, 16(2), 63-77.

Chew, T., Ho, K. A., \& Loo, C. K. (2015). Inter-and intra-individual variability in response to transcranial direct current stimulation (tDCS) at varying current intensities. Brain Stimulation, 8(6), 1130-1137.

Chhatbar, P. Y., Ramakrishnan, V., Kautz, S., George, M. S., Adams, R. J., \& Feng, W. (2016). Transcranial Direct Current Stimulation Post-Stroke Upper Extremity Motor Recovery Studies Exhibit a Dose-Response Relationship. Brain stimulation, 9(1), 16-26.

Cohen, J. R., Berkman, E. T., \& Lieberman, M. D. (2013). Intentional and incidental self-control in ventrolateral prefrontal cortex. In Principles of frontal lobe function (pp. 417-440). Oxford University Press, New York.

Cohen, J. D., McClure, S. M., \& Angela, J. Y. (2007). Should I stay or should I go? How the human brain manages the trade-off between exploitation and 
exploration. Philosophical Transactions of the Royal Society B: Biological Sciences, 362(1481), 933-942.

Conrad, K. L., Ford, K., Marinelli, M., \& Wolf, M. E. (2010). Dopamine receptor expression and distribution dynamically change in the rat nucleus accumbens after withdrawal from cocaine selfadministration. Neuroscience, 169(1), 182-194.

Copolov, D. L., Link, C. G. G., \& Kowalcyk, B. (2000). A multicentre, doubleblind, randomized comparison of quetiapine (ICI 204,636,'Seroquel') and haloperidol in schizophrenia. Psychological medicine, 30(1), 95-105.

Colzato, L. S., Sellaro, R., van den Wildenberg, W. P., \& Hommel, B. (2015). tDCS of medial prefrontal cortex does not enhance interpersonal trust. Journal of Psychophysiology.

Congdon, E., \& Canli, T. (2005). The endophenotype of impulsivity: reaching consilience through behavioral, genetic, and neuroimaging approaches. Behavioral and cognitive neuroscience reviews, 4(4), 262281.

Correll, J., Hudson, S. M., Guillermo, S., \& Ma, D. S. (2014). The police officer's dilemma: A decade of research on racial bias in the decision to shoot. Social and Personality Psychology Compass, 8(5), 201-213.

Correll, J., Urland, G. R., \& Ito, T. A. (2006). Event-related potentials and the decision to shoot: The role of threat perception and cognitive control. Journal of Experimental Social Psychology, 42(1), 120-128. 
Costa, A., la Fougère, C., Pogarell, O., Möller, H. J., Riedel, M., \& Ettinger, U. (2013). Impulsivity is related to striatal dopamine transporter availability in healthy males. Psychiatry Research: Neuroimaging, 211(3), 251-256.

Cyders, M. A., \& Coskunpinar, A. (2011). Measurement of constructs using selfreport and behavioral lab tasks: is there overlap in nomothetic span and construct representation for impulsivity?. Clinical psychology review, 31(6), 965-982.

Dalley, J. W., Fryer, T. D., Brichard, L., Robinson, E. S., Theobald, D. E., Lääne, K., .. \& Abakumova, I. (2007). Nucleus accumbens D2/3 receptors predict trait impulsivity and cocaine reinforcement. science, 315(5816), 12671270.

Dalley, J. W., \& Roiser, J. P. (2012). Dopamine, serotonin and impulsivity. Neuroscience, 215, 42-58.

Datta, A. (2012). Inter-individual variation during transcranial direct current stimulation and normalization of dose using MRI-derived computational models. Frontiers in psychiatry, 3, 91.

Daw, N. D., O'doherty, J. P., Dayan, P., Seymour, B., \& Dolan, R. J. (2006). Cortical substrates for exploratory decisions in humans. Nature, 441(7095), 876.

Derringer, J., Krueger, R. F., Dick, D. M., Saccone, S., Grucza, R. A., Agrawal, A., ... \& Nurnberger Jr, J. I. (2010). Predicting sensation seeking from dopamine genes: A candidate-system approach. Psychological Science, 21(9), 1282-1290. 
DeYoung, C. G. (2013). The neuromodulator of exploration: A unifying theory of the role of dopamine in personality. Frontiers in Human Neuroscience, 7 , 762.

DeYoung, C. G. (2010). Impulsivity as a personality trait. Handbook of selfregulation: Research, theory, and applications, 2, 485-502.

Erdfelder, E., Faul, F., \& Buchner, A. (1996). GPOWER: A general power analysis program. Behavior research methods, instruments, \& computers, 28(1), 1-11.

Fecteau, S., Pascual-Leone, A., Zald, D. H., Liguori, P., Théoret, H., Boggio, P. S., \&

Fregni, F. (2007). Activation of prefrontal cortex by transcranial direct current stimulation reduces appetite for risk during ambiguous decision Journal of Neuroscience, 27(23), 6212-6218.

Fregni, F., Boggio, P. S., Santos, M. C., Lima, M., Vieira, A. L., Rigonatti, S. P., ... \& Pascual-Leone, A. (2006). Noninvasive cortical stimulation with transcranial direct current stimulation in Parkinson's disease. Movement disorders, 21(10), 1693-1702.

Fredholm, B. B. (1995). Adenosine, adenosine receptors and the actions of caffeine. Pharmacology \& toxicology, 76(2), 93-101.

Filmer, H. L., Dux, P. E., \& Mattingley, J. B. (2014). Applications of transcranial direct current stimulation for understanding brain function. Trends in neurosciences, 37(12), 742-753. 
Finkel, E. J. (2014). The I3 model: Metatheory, theory, and evidence. In Advances in experimental social psychology (Vol. 49, pp. 1-104). Academic Press.

Flaten, M. A., Aasli, O., \& Blumenthal, T. D. (2003). Expectations and placebo responses to caffeine-associated stimuli. Psychopharmacology, 169(2), 198-204.

Fredholm, B. B., Bättig, K., Holmén, J., Nehlig, A., \& Zvartau, E. E. (1999). Actions of caffeine in the brain with special reference to factors that contribute to its widespread use. Pharmacological reviews, 51(1), 83-133.

Fregni, F., Boggio, P. S., Nitsche, M., Bermpohl, F., Antal, A., Feredoes, E., ... \& Pascual-Leone, A. (2005). Anodal transcranial direct current stimulation of prefrontal cortex enhances working memory. Experimental brain research, 166(1), 23-30.

Galtress, T., \& Kirkpatrick, K. (2010). The role of the nucleus accumbens core in impulsive choice, timing, and reward processing. Behavioral neuroscience, 124(1), 26.

Gebodh, N., Esmaeilpour, Z., Adair, D., Schestattsky, P., Fregni, F., \& Bikson, M. (2019). Transcranial Direct Current Stimulation Among Technologies for Low-Intensity Transcranial Electrical Stimulation: Classification, History, and Terminology. In Practical Guide to Transcranial Direct Current Stimulation (pp. 3-43). Springer, Cham. 
Gelman, A., Hill, J., \& Yajima, M. (2012). Why we (usually) don't have to worry about multiple comparisons. Journal of Research on Educational Effectiveness, 5(2), 189-211.

Georgii, C., Goldhofer, P., Meule, A., Richard, A., \& Blechert, J. (2017). Food craving, food choice and consumption: The role of impulsivity and shamcontrolled tDCS stimulation of the right dIPFC. Physiology \& Behavior, $177,20-26$.

Gillespie, N. A., Aggen, S. H., Gentry, A. E., Neale, M. C., Knudsen, G. P., Krueger, R. F., ... \& Rosenström, T. H. (2018). Testing Genetic and Environmental Associations Between Personality Disorders and Cocaine Use: A Population-Based Twin Study. Twin Research and Human Genetics, 21(1), 24-32

Gladwin, T. E., den Uyl, T. E., \& Wiers, R. W. (2012). Anodal tDCS of dorsolateral prefontal cortex during an Implicit Association Test. Neuroscience

Gomez-Ariza, C. J., Martín, M. C., \& Morales, J. (2017). Tempering proactive cognitive control by means of tDCS of the lateral prefrontal cortex. Brain Stimulation: Basic, Translational, and Clinical Research in Neuromodulation, 10(2), 360.

Grace, A. (1991). Phasic versus tonic dopamine release and the modulation of dopamine system responsivity: a hypothesis for the etiology of schizophrenia. Neuroscience 41, I-24. Herkenham M. and Nauta WJH (1977) Afferent connections of the habenular nuclei in the rat. A 
horseradish peroxidase study, with a note on the fiber-of-passage problem. J. camp. Neural, 173, 123-146.

Gruber, A. J., \& O'Donnell, P. (2009). Bursting activation of prefrontal cortex drives sustained up states in nucleus accumbens spiny neurons in vivo. Synapse, 63(3), 173-180.

Hoy, K. E., Emonson, M. R., Arnold, S. L., Thomson, R. H., Daskalakis, Z. J., \& Fitzgerald, P. B. (2013). Testing the limits: investigating the effect of tDCS dose on working memory enhancement in healthy controls. Neuropsychologia, 51(9), 1777-1784.

Hsu, T. Y., Juan, C. H., \& Tseng, P. (2016). Individual differences and statedependent responses in transcranial direct current stimulation. Frontiers in human neuroscience, 10, 643.

Hsu, T. Y., Tseng, L. Y., Yu, J. X., Kuo, W. J., Hung, D. L., Tzeng, O. J., ... \& Juan, C. H. (2011). Modulating inhibitory control with direct current stimulation of the superior medial frontal cortex. Neuroimage, 56(4), 22492257.

Huang, D., Chen, S., Wang, S., Shi, J., Ye, H., Luo, J., \& Zheng, H. (2017). Activation of the DLPFC reveals an asymmetric effect in risky decision making: evidence from a tDCS study. Frontiers in psychology, 8.

Iversen, S. D., \& Iversen, L. L. (2007). Dopamine: 50 years in perspective. Trends in neurosciences, 30(5), 188-193. 
Jacobson, L., Koslowsky, M., \& Lavidor, M. (2012). tDCS polarity effects in motor and cognitive domains: a meta-analytical review. Experimental brain research, 216(1), 1-10.

Jauch-Chara, K., Kistenmacher, A., Herzog, N., Schwarz, M., Schweiger, U., \& Oltmanns, K. M. (2014). Repetitive electric brain stimulation reduces food intake in humans. The American journal of clinical nutrition, 100(4), 10031009.

Johansson, E., \& Halldin, M. M. (1989). Urinary excretion half-life of $\Delta 1$ tetrahydrocannabinol-7-oic acid in heavy marijuana users after smoking. Journal of analytical toxicology, 13(4), 218-223.

Johnson, P. O., \& Fay, L. C. (1950). The Johnson-Neyman technique, its theory and application. Psychometrika, 15(4), 349-367.

Kanai, R., \& Rees, G. (2011). The structural basis of inter-individual differences in human behaviour and cognition. Nature Reviews Neuroscience, 12(4), 231.

Katz, B., Au, J., Buschkuehl, M., Abagis, T., Zabel, C., Jaeggi, S. M., \& Jonides, J. (2017). Individual differences and long-term consequences of tDCSaugmented cognitive training. Journal of cognitive neuroscience, 29(9), 1498-1508.

Kelley, N. J., Hortensius, R., \& Harmon-Jones, E. (2013). When anger leads to rumination: Induction of relative right frontal cortical activity with transcranial direct current stimulation increases anger-related rumination. Psychological science, 24(4), 475-481. 
Kertzman, S., Vainder, M., Aizer, A., Kotler, M., \& Dannon, P. N. (2017). Pathological gambling and impulsivity: Comparison of the different measures in the behavior inhibition tasks. Personality and Individual Differences, 107, 212-218.

Kim, J. H., Kim, D. W., Chang, W. H., Kim, Y. H., Kim, K., \& Im, C. H. (2014). Inconsistent outcomes of transcranial direct current stimulation may originate from anatomical differences among individuals: electric field simulation using individual MRI data. Neuroscience letters, 564, 6-10.

Kiyatkin, E. A., \& Lenoir, M. (2012). Rapid fluctuations in extracellular brain glucose levels induced by natural arousing stimuli and intravenous cocaine: fueling the brain during neural activation. American Journal of Physiology-Heart and Circulatory Physiology.

Krause, B., \& Cohen Kadosh, R. (2014). Not all brains are created equal: the relevance of individual differences in responsiveness to transcranial electrical stimulation. Frontiers in systems neuroscience, 8, 25.

Kuo, H. I., Paulus, W., Batsikadze, G., Jamil, A., Kuo, M. F., \& Nitsche, M. A. (2016). Chronic enhancement of serotonin facilitates excitatory transcranial direct current stimulation-induced neuroplasticity. Neuropsychopharmacology, 41(5), 1223.

Kuo, H. I., Paulus, W., Batsikadze, G., Jamil, A., Kuo, M. F., \& Nitsche, M. A. (2017). Acute and chronic effects of noradrenergic enhancement on transcranial direct current stimulation-induced neuroplasticity in humans. The Journal of physiology, 595(4), 1305-1314. 
Kuo, M. F., Paulus, W., \& Nitsche, M. A. (2007). Boosting focally-induced brain plasticity by dopamine. Cerebral Cortex, 18(3), 648-651.

Lee, K. W., Kim, Y., Kim, A. M., Helmin, K., Nairn, A. C., \& Greengard, P. (2006). Cocaine-induced dendritic spine formation in D1 and D2 dopamine receptor-containing medium spiny neurons in nucleus accumbens. Proceedings of the National Academy of Sciences, 103(9), 3399-3404.

Lejuez, C. W., Read, J. P., Kahler, C. W., Richards, J. B., Ramsey, S. E., Stuart, G. L., ... \& Brown, R. A. (2002). Evaluation of a behavioral measure of risk taking: the Balloon Analogue Risk Task (BART). Journal of Experimental Psychology: Applied, 8(2), 75.

Lieberman, M. D., \& Eisenberger, N. I. (2008). The pains and pleasures of social life: A social cognitive neuroscience approach. NeuroLeadership Journal, 1, 38-43.

Li, Y., Kolb, B., \& Robinson, T. E. (2003). The location of persistent amphetamine-induced changes in the density of dendritic spines on medium spiny neurons in the nucleus accumbens and caudateputamen. Neuropsychopharmacology, 28(6), 1082.

Lipszyc, J., \& Schachar, R. (2010). Inhibitory control and psychopathology: a meta-analysis of studies using the stop signal task. Journal of the International Neuropsychological Society, 16(6), 1064-1076.v

Ljubisavljevic, M., Maxood, K., Bjekic, J., Oommen, J., \& Nagelkerke, N. (2016). Long-term effects of repeated prefrontal cortex transcranial direct current 
stimulation (tDCS) on food craving in normal and overweight young adults. Brain stimulation, 9(6), 826-833.

Logan, G. D. (1994). On the ability to inhibit thought and action: A users' guide to the stop signal paradigm. In D. Dagenbach \& T. H. Carr (Eds.), Inhibitory processes in attention, memory, and language (pp. 189-239). San Diego, CA, US: Academic Press.

Masi, C., Dinnella, C., Pirastu, N., Prescott, J., \& Monteleone, E. (2016). Caffeine metabolism rate influences coffee perception, preferences and intake. Food quality and preference, 53, 97-104.

Matson, J. L., \& Mahan, S. (2010). Antipsychotic drug side effects for persons with intellectual disability. Research in developmental disabilities, 31(6), 1570-1576.

McLaren, M. E., Nissim, N. R., \& Woods, A. J. (2018). The effects of medication use in transcranial direct current stimulation: A brief review. Brain Stimulation: Basic, Translational, and Clinical Research in Neuromodulation, 11(1), 52-58.

Mead, N. L., Baumeister, R. F., Gino, F., Schweitzer, M. E., \& Ariely, D. (2009). Too tired to tell the truth: Self-control resource depletion and dishonesty. Journal of experimental social psychology, 45(3), 594-597. Moeller, F. G., Dougherty, D. M., Barratt, E. S., Oderinde, V., Mathias, C. W., Harper, R. A., \& Swann, A. C. (2002). Increased impulsivity in cocaine dependent subjects independent of antisocial personality disorder and aggression. Drug and alcohol dependence, 68(1), 105-111. 
Monte-Silva, K., Kuo, M. F., Thirugnanasambandam, N., Liebetanz, D., Paulus, W., \& Nitsche, M. A. (2009). Dose-dependent inverted U-shaped effect of dopamine (D2-like) receptor activation on focal and nonfocal plasticity in humans. Journal of Neuroscience, 29(19), 6124-6131.

Monte-Silva, K., Liebetanz, D., Grundey, J., Paulus, W., \& Nitsche, M. A. (2010). Dosage-dependent non-linear effect of I-dopa on human motor cortex plasticity. The Journal of physiology, 588(18), 3415-3424.

Müller, H. L., Handwerker, G., Gebhardt, U., Faldum, A., Emser, A., Kolb, R., \& Sörensen, N. (2006). Melatonin treatment in obese patients with childhood craniopharyngioma and increased daytime sleepiness. Cancer Causes \& Control, 17(4), 583-589.

Muraven, M., Rosman, H., \& Gagné, M. (2007). Lack of autonomy and selfcontrol: Performance contingent rewards lead to greater depletion. Motivation and Emotion, 31(4), 322-330.

Muraven, M., \& Shmueli, D. (2006). The self-control costs of fighting the temptation to drink. Psychology of Addictive Behaviors, 20(2), 154.

Narayan, Veena Madhavi. Mapping the Neural Substrates of Impulsivity. University of California, Los Angeles, 2010.

Nestler, E. J. (2005). The neurobiology of cocaine addiction. Science \& practice perspectives, 3(1), 4 .

Netter, P., Hennig, J., \& Roed, I. S. (1996). Serotonin and dopamine as mediators of sensation seeking behavior. Neuropsychobiology, 34(3), 155165. 
Nikolin, S., Martin, D., Loo, C., \& Boonstra, T. (2019). Dosage effects of tDCS on working memory and neurophysiological outcomes. Brain Stimulation: Basic, Translational, and Clinical Research in Neuromodulation, 12(2), $482-483$.

Nitsche, M. A., Kuo, M. F., Karrasch, R., Wächter, B., Liebetanz, D., \& Paulus, W. (2009). Serotonin affects transcranial direct current-induced neuroplasticity in humans. Biological psychiatry, 66(5), 503-508.

Nitsche, M. A., \& Paulus, W. (2000). Excitability changes induced in the human motor cortex by weak transcranial direct current stimulation. The Journal of physiology, 527(3), 633-639.

Norbury, A., Manohar, S., Rogers, R. D., \& Husain, M. (2013). Dopamine modulates risk-taking as a function of baseline sensation-seeking trait. Journal of Neuroscience, 33(32), 12982-12986.

Nord, C. L., Forster, S., Halahakoon, D. C., Penton-Voak, I. S., Munafò, M. R., \& Roiser, J. P. (2017 Maréchal, M. A., Cohn, A., Ugazio, G., \& Ruff, C. C. (2017). Increasing honesty in humans with noninvasive brain stimulation. Proceedings of the National Academy of Sciences, 114(17), 4360-4364.

Nosek, B. A., \& Banaji, M. R. (2001). The go/no-go association task. Social cognition, 19(6), 625-666.

Parkinson, J. A., Olmstead, M. C., Burns, L. H., Robbins, T. W., \& Everitt, B. J. (1999). Dissociation in effects of lesions of the nucleus accumbens core and shell on appetitive pavlovian approach behavior and the potentiation 
of conditioned reinforcement and locomotor activity bydamphetamine. Journal of Neuroscience, 19(6), 2401-2411.

Pickering, C., \& Kiely, J. (2018). Are the current guidelines on caffeine use in sport optimal for everyone? Inter-individual variation in caffeine ergogenicity, and a move towards personalised sports nutrition. Sports Medicine, 48(1), 7-16.

Plant, E. A., \& Peruche, B. M. (2005). The consequences of race for police officers' responses to criminal suspects. Psychological Science, 16(3), 180-183.

Pripfl, J., Neumann, R., Köhler, U., \& Lamm, C. (2013). Effects of transcranial direct current stimulation on risky decision making are mediated by 'hot'and 'cold'decisions, personality, and hemisphere. European Journal of Neuroscience, 38(12), 3778-3785.

Prisciandaro, J. J., McRae-Clark, A. L., Myrick, H., Henderson, S., \& Brady, K. T. (2014). Brain activation to cocaine cues and motivation/treatment status. Addiction biology, 19(2), 240-249.

Quarta, D., Ferré, S., Solinas, M., You, Z. B., Hockemeyer, J., Popoli, P., \& Goldberg, S. R. (2004). Opposite modulatory roles for adenosine A1 and $\mathrm{A} 2 \mathrm{~A}$ receptors on glutamate and dopamine release in the shell of the nucleus accumbens. Effects of chronic caffeine exposure. Journal of neurochemistry, 88(5), 1151-1158.

Robinson, T. E., \& Becker, J. B. (1986). Enduring changes in brain and behavior produced by chronic amphetamine administration: a review and evaluation 
of animal models of amphetamine psychosis. Brain research reviews, 11(2), 157-198.

Riva, P., Romero Lauro, L. J., DeWall, C. N., Chester, D. S., \& Bushman, B. J. (2014). Reducing aggressive responses to social exclusion using transcranial direct current stimulation. Social cognitive and affective neuroscience, 10(3), 352-356.

Rubia, K., Oosterlaan, J., Sergeant, J. A., Brandeis, D., \& Leeuwen, T. V. (1998). Inhibitory dysfunction in hyperactive boys. Behavioural brain research, 94(1), 25-32.

Sellaro, R., Derks, B., Nitsche, M. A., Hommel, B., van den Wildenberg, W. P., van

Dam, K., \& Colzato, L. S. (2015). Reducing prejudice through brain stimulation. Brain stimulation, 8(5), 891-897.s[E:

Scott, K., Ma, D. S., Sadler, M. S., \& Correll, J. (2017). A social scientific approach toward understanding racial disparities in police shooting: Data from the Department of Justice (1980-2000). Journal of Social Issues, 73(4), 701-722.

Solanto, M. V. (2002). Dopamine dysfunction in AD/HD: integrating clinical and basic neuroscience research. Behavioural brain research, 130(1-2), 65-71.

Solanto, M. V., Abikoff, H., Sonuga-Barke, E., Schachar, R., Logan, G. D., Wigal, T., ... \& Turkel, E. (2001). The ecological validity of delay aversion and response inhibition as measures of impulsivity in AD/HD: a supplement to 
the NIMH multimodal treatment study of AD/HD. Journal of abnormal child psychology, 29(3), 215-228.

Solinas, M., Ferre, S., You, Z. B., Karcz-Kubicha, M., Popoli, P., \& Goldberg, S. R. (2002). Caffeine induces dopamine and glutamate release in the shell of the nucleus accumbens. Journal of Neuroscience, 22(15), 6321-6324.

Strafella, A. P., Paus, T., Barrett, J., \& Dagher, A. (2001). Repetitive transcranial magnetic stimulation of the human prefrontal cortex induces dopamine release in the caudate nucleus. Journal of Neuroscience, 21(15), RC157RC157.

Tanaka, T., Takano, Y., Tanaka, S., Hironaka, N., Kobayashi, K., Hanakawa, T., ... \& Honda, M. (2013). Transcranial direct-current stimulation increases extracellular dopamine levels in the rat striatum. Frontiers in systems neuroscience, 7, 6 .

Tarizzo, V., \& Rubio, M. C. (1985). Effects of cocaine on several adrenergic system parameters. General pharmacology, 16(1), 71-74.

Verbruggen, F., Logan, G. D., \& Stevens, M. A. (2008). STOP-IT: Windows executable software for the stop-signal paradigm. Behavior research methods, 40(2), 479-483.

Volkow, N. D., Wang, G. J., Logan, J., Alexoff, D., Fowler, J. S., Thanos, P. K., ... \& Tomasi, D. (2015). Caffeine increases striatal dopamine D 2/D 3 receptor availability in the human brain. Translational psychiatry, 5(4), e549. 
Weiss, R. D., Mirin, S. M., Griffin, M. L., Gunderson, J. G., \& Hufford, C. (1993). Personality disorders in cocaine dependence. Comprehensive Psychiatry, 34(3), 145-149.

Yanofski, J. (2010). The dopamine dilemma: using stimulants and antipsychotics concurrently. Psychiatry (Edgmont), 7(6), 18.

Zald, D. H., Cowan, R. L., Riccardi, P., Baldwin, R. M., Ansari, M. S., Li, R., et al. (2008). Midbrain dopamine receptor availability is inversely associated with novelty-seeking traits in humans. J. Neurosci. 28, 14372-14378.

Zheng, H., Wang, S., Guo, W., Chen, S., Luo, J., Ye, H., \& Huang, D. (2017). Enhancing the Activity of the DLPFC with tDCS Alters Risk Preference without Changing Interpersonal Trust. Frontiers in neuroscience, 11.

Zuckerman, M. (1996). The psychobiological model for impulsive unsocialized sensation seeking: A comparative approach. Neuropsychobiology, 34(3), 125-129. 
VITA

Sarah Elizabeth Bell

Birth place: Nashville, Tennessee

\section{Education}

Hendrix College, 2008-2011

B.A. in Psychology, minor in Gender Studies

University of Kentucky, 2015-2017

Master's degree in Experimental Psychology

University of Kentucky, 2017-2019 (expected)

Doctor of Philosophy in Experimental Psychology

\section{Positions}

2011

2012-2015

2015-2016

2017

2018

2017-2019

2019-
Social Worker, Arkansas Children's Hospital

Child Advocate, Women's Shelter of Central Arkansas

Teaching Assistant, University of Kentucky

Instructor, Eastern Kentucky University

Instructor, Transylvania University, Kentucky

Instructor, University of Kentucky

Statistician, OU-Tulsa School of Community Medicine

\section{Peer-reviewed Publications}

1. Chester, D.S., Bell, S.B., DeWall, C.N., West, S.J., Romero-Lopez, M., \& Craig, A.W. (in press) Neural Correlates of Intertemporal Choice in Aggressive Behavior. Journal of Aggressive Behavior. 
2. Bell, S.B., \& DeWall, C.N. (in press). Pressing the rewarding button: The relationship between impulsivity, fatigue, and reward sensitivity. Journal of Research in Personality.

3. Bell, S.B. \& DeWall, C.N. (2018) Does transcranial direct current stimulation to the prefrontal cortex affect social behavior? A metaanalysis. Social cognitive and affective neuroscience, 13(9), 899-906.

4. Bell, S.B \& DeWall, C.N. (2018). Stigmatism and ostracism. In T. Shackelford \& V. Weekes-Shackelford (Eds.), Encyclopedia of Evolutionary Psychological Science. Springer International Publishing.

5. Enjaian, B.M. Bell, S.B., Whitt, Z.* \& DeWall, C.N. (2018). Socialcognitive processes in the development of antisocial and violent behavior. In A.T. Vazonyi, D.J. Fannery, \& M. DeLisi (Eds.) The Cambridge Handbook of Violent Behavior and Aggression, 2ndedition. Cambridge: Cambridge University Press.

6. DeWall, C. N., Bell, S.B., \& Enjaian, B.M. (2016). Only the lonely: The curious case of exclusion and rejection. In K. Williams \& S. Nida (Eds.), Frontiers handbook of ostracism, social exclusion, and rejection. New York, NY: Psychology Press. 